\title{
Investigation of pressure drop in horizontal pipes with different diameters
}

\author{
F.A. Hamad ${ }^{1}$, F. Faraji ${ }^{2}$, C.G.S. Santim ${ }^{3}$, N. Basha ${ }^{4}$, Z. Ali $^{5}$
}

1. School of Science \& Engineering, Teesside University, Middlesbrough, TS1 3BA, UK, f.hamad@tees.ac.uk

2. School of Science \& Engineering, Teesside University, Middlesbrough, TS1 3BA, UK, foadfaraji5@gmail.com

3. Faculty of Mechanical Engineering, University of Campinas, CEP: 13083-860, Campinas, Brazil, christianosantim@gmail.com

4. School of Science \& Engineering, Teesside University, Middlesbrough, TS1 3BA, UK, n.mehboobbasha@tees.ac.uk

5. School of Science \& Engineering, Teesside University, Middlesbrough, TS13BA, UK, z.ali@tees.ac.uk 


\begin{abstract}
The pressure drop has a significant importance in multiphase flow systems. In this paper, the effect of the volumetric quality and mixture velocity on pressure drop of gas-liquid flow in horizontal pipes of different diameters are investigated experimentally and numerically. The experimental facility was designed and built to measure the pressure drop in three pipes of $12.70,19.05$ and $25.40 \mathrm{~mm}$. The water and air flow rates can be adjusted to control the mixture velocity and void fraction. The measurements are performed under constant water flow rate (CWF) by adding air to the water and constant total flow rate (CTF) in which the flow rates for both phases are changed to give same CTF. The drift-flux model is also used to predict the pressure drop for same cases. The present data is also compared with a number of empirical models from the literature. The results show that: i) the pressure drop increases with higher volumetric qualities for the cases of constant water flow rate but decreases for higher volumetric qualities of constant total flow rate due to the change in flow pattern. ii) The drift-flux model and homogenous model are the most suitable models for pressure drop prediction.
\end{abstract}

KEYWORDS: Air-water flow, pressure drop, horizontal pipes, experimental measurement, drift-flux model

\title{
Highlights:
}

1. The pressure drop in three horizontal pipes of $12.70,19.05$ and $25.40 \mathrm{~mm}$ is studied.

2. The pressure drop increases with higher volumetric qualities for the cases of constant water flow rate but decreases for higher volumetric qualities of constant total flow rate due to the change in flow pattern

3. The drift-flux model and homogenous model are the most suitable models for pressure drop prediction. 


\section{Introduction}

The application of single and multiphase flow has been frequently observed in many diverse fields of science and engineering such as agricultural, biomedical, chemical, food science and petroleum engineering. It is necessary to predict design parameters such as friction factor, pressure drop, bubble size, void fraction, heat and mass transfer coefficient in order to determine the desired operating conditions and the size of the equipment required for the specific application. The pressure drop in horizontal pipes is the parameter to be investigated in this paper

The pressure drop in horizontal pipes has been studied by a number of researchers to develop empirical models to use in the design of new equipment. However, there is no general model available to predict the pressure drop within acceptable accuracy (Michaelides, 2006). This is attributed to the complexities inherited from the single-phase flow like the non-linearity, transition to turbulence and instabilities plus additional two-phase characteristics like motion and deformation of the interface, non-equilibrium effects and interactions between the phases (Ghajar, 2005).

In horizontal flow, the phases tend to separate due to the difference in densities and the effect of fluid gravity, thereby causing a form of stratification. The heavier fluid tends to concentrate at the bottom of the pipe whereas the lighter fluid concentrates at the top. Several flow patterns can be observed during the flow of mixed phases as flow rates of water and air are varied. These flow patterns also depend on the physical properties of the fluids such as the density and viscosity, surface tension and the flow system geometry.

According to Awad (2012) the formation of specific flow pattern is governed by competition of different forces in the system such as momentum, viscous, gravitational, and surface tension. When the momentum force in two-phase flow is dominant, the bubbles tend to disperse uniformly into the pipe. This usually occurs at high mixture flow rate, which leads to a bubbly flow.

The pressure drop of a fluid is due to the variation of kinetic and potential energy of the fluid and that is due to friction on the walls of the flow channel. Therefore, the total pressure drop is represented by the sum of the static pressure drop (elevation head), the momentum pressure drop (acceleration) and the frictional pressure drop. 
Here the most problematic and important term is the frictional pressure drop, which can be expressed as a function of the two-phase friction factor.

Two distinct approaches are available from engineering point of view in accounting for the behaviour of multiphase flow system. The first is a global approach that relies on the practical method in developing simplified models that contain parameters, which are evaluated from the experimental data (Lockhart and Martinelli, 1949; Friedel, 1979; Mishima and Hibiki, 1996; Chen et al., 2001). The second is a continuum approach in which more complex physically-based models are used to describe the flow phenomena (Ivor, et al., 2004; Beattie and Whalley, 1982; Awad and Muzychka, 2014a; Awad and Muzychka, 2014b). The two-phase frictional pressure drop in gas-liquid flow is determined by either finding of two-phase friction factor (homogeneous flow model) or a two phase friction multiplier (separated flow model). A summary of the empirical models is given hereafter.

\section{Review of two-phase frictional pressure drop correlation}

\subsection{Homogeneous flow model}

In Homogenous model, it is assumed that there is no slip between the two phase flow at similar velocities. However, with an exception for very small values of void fraction (bubbly flow region) there exists a significant slip between the two phases (Bhagwat and Ghajar (2014)).

The frictional pressure drop equation is the Darcy equation which uses Blasius relation to calculate the friction factor from the average mixture properties. The Blasius equation for two-phase flow is represented by:

$$
f_{T P}=0.079 / \mathrm{Re}_{m}^{-0.25},
$$

where $\operatorname{Re}_{m}=G_{m} d / \mu_{m}$ is the mixture Reynolds number, $f_{T P}$ is the two-phase flow friction factor, $G_{m}$ : mass flus $\left(\mathrm{kg} / \mathrm{m}^{2} \mathrm{~s}\right), \mathrm{d}$ is the pipe diameter $(\mathrm{m})$

The mixture viscosity $\left(\mu_{m}\right)$ is represented as in Awad (2014), in terms of the mass quality (x): 


$$
\mu_{m}=x \mu_{g}+(1-x) \mu_{l}
$$

Where $\mathrm{x}$ is the mass quality, $\mu_{g}$ is the gas viscosity $\left(\mathrm{N} . \mathrm{s} / \mathrm{m}^{2}\right), \mu_{l}$ is the liquid viscosity $\left(\mathrm{N} . \mathrm{s} / \mathrm{m}^{2}\right)$

Rodrigo et all (2016) studied experimentally the pressure drop of multicomponent zeotropic mixtures boiling in small channels over temperatures ranging from $100 \mathrm{~K}$ to room temperature along with the sensitivity of frictional pressure drop to parameters such as mass flux, pressure, tube diameter, and mixture composition. The measured data were compared to several pressure drop correlations available in the literature. They found that Awad and Muzychka (definition 1) correlation (Awad and Muzychka, 2008) for multiphase flow viscosity was able to predict the pressure drop over the range of experimental data considered, with an Absolute Average Deviation (AAD) of $17 \%$. Awad and Muzychka (2008) (definition 1) is also used in this study to predict the pressure drop for all the tests in present work. The viscosity is given as:

$$
\mu_{2 p h}=\mu_{l} \frac{2 \mu_{l}+\mu_{a}-2\left(\mu_{l}-\mu_{a}\right) x}{2 \mu_{l}+\mu_{a}+\left(\mu_{l}-\mu_{a}\right) x}
$$

Whereas, the mixture density $\left(\rho_{m}\right)$ can be evaluated as (Awad and Muzychka, 2008; Awad 2015):

$$
\rho_{m}=\alpha \rho_{g}+(1-\alpha) \rho_{l}
$$

Where $\alpha$ is void fraction, $\rho_{g}$ is the gas density $\left(\mathrm{kg} / \mathrm{m}^{3}\right), \rho_{l}$ is the liquid density, $\left(\mathrm{kg} / \mathrm{m}^{3}\right)$

Based on the above average properties, two phase frictional pressure drop for horizontal tube of internal diameter, $d$ is calculated as:

$$
\Delta p=\frac{2 f_{T P} G_{m}^{2} l}{\rho_{m} d}
$$

Where $l$ is the length of the pipe. The homogenous model becomes more accurate for density ratio lower than 10 and mass flux lower than $2000 \mathrm{~kg} / \mathrm{m}^{2} \mathrm{~s}$ (Crowe, 2006). 


\subsection{Separated flow models}

\subsubsection{Lockhart-Martinelli (1949)}

The Lockhart-Martinelli pressure drop correlation is the most typical form of separated flow model. A majority of correlation that has been proposed by many researchers such as (Friedel, 1979; Mishima and Hibiki, 1996; Chen et., 2001) were proposed on the basis of two-phase friction multiplier suggested by Lockhart and Martinelli (1949) and the fitting correlation of the multipliers from Chisholm (1983).

Lockhart and Martinelli (1949) performed the most representative investigation that developed the theory of separated flow model. Their work based on experimental analysis of a circular pipe with the diameter ranging from 1.48 to $25.83 \mathrm{~mm}$ using two phase mixture of air with benzene, kerosene, water and several oils. Their work was based on two hypotheses, the first assumption states that the static pressure drop for both liquid and gas phases are the same regardless of the flow pattern as long as the changes in radial direction are not significant and the second assumption states that the total volume of the pipe is equal to sum of the volume occupied by gas and liquid at any instant (continuity equation). Based on these assumptions and their experimental analysis, Lockhart and Martinelli (1949) developed the concept of twophase flow multipliers which can be used to calculate the two-phase flow pressure drop $(d p / d x)_{T P}$ as ((Holland and Bragg, 1995) :

$$
\left(\frac{d p}{d x}\right)_{T P}=\phi_{l}^{2}\left(\frac{d p}{d x}\right)_{l}
$$

Chisholm (1983) developed the theoretical basis to calculate the liquid phase multiplier $\phi_{l}^{2}$ from the following simplified correlation,

$$
\phi_{l}^{2}=1+\frac{c}{X}+\frac{1}{X^{2}}
$$

where

$$
X=\sqrt{(d p / d x)_{l} /(d p / d x)_{g}} \text {. }
$$


The values of $C$ are into the range of $5 \leq C \leq 20$ for different flow regimes, as given in Table 1.

Table 1. The values of coefficient C (Holland and Bragg, 1999).

\begin{tabular}{|c|c|c|}
\hline Liquid & Gas & C \\
\hline Turbulent & Turbulent & 20 \\
\hline Viscous & Turbulent & 12 \\
\hline Turbulent & Viscous & 10 \\
\hline Viscous & Viscous & 5 \\
\hline
\end{tabular}

\subsubsection{The Friedel correlation (1979)}

Friedel model is one of the most accurate methods to determine the pressure drop in two-phase flow (Quiben (2005)). Friedel developed a correlation based on 16.000 measured data points and for wide range of pipe diameters. The model includes the gravity effect through the Froude number (Fr), the effects of surface tension and total mass flux using the Weber number (We) (Suwankamnerd \& Wongwises, 2014).

The two-phase flow pressure drop, $\left(\frac{d p}{d x}\right)_{T P}$ can be obtained as:

$$
\left(\frac{d p}{d x}\right)_{T P}=\phi_{l o}^{2}\left(\frac{d p}{d x}\right)_{l o}
$$

Where $\phi_{l o}^{2}$ is the two-phase friction multiplier based on pressure gradient for total flow assumed liquid. It can be calculated from the following equation:

$$
\varphi_{l o}^{2}=E+\frac{3.24 F H}{\operatorname{Fr}^{0.45} \mathrm{We}^{0.035}},
$$

The Froude and weber numbers are given respectively as $F r=\frac{G_{m}^{2}}{g d \rho_{m}^{2}}$ and $W e=\frac{G_{m}^{2} d}{\rho_{m} \sigma}$ 
where $\sigma$ is the surface tension. The dimensionless parameters $F, H$ and $E$ (Thome, (1990)) are defined as follows:

$$
\begin{gathered}
E=(1-x)^{2}+x^{2} \frac{\rho_{l} f_{g o}}{\rho_{g} f_{l o}}, \\
F=x^{0.78}(1-x)^{0.224}, \\
H=\left(\frac{\rho_{l}}{\rho_{g}}\right)^{0.91}\left(\frac{\mu_{g}}{\mu_{l}}\right)^{0.19}\left(1-\frac{\mu_{g}}{\mu_{l}}\right)^{0.7} .
\end{gathered}
$$

The $f_{l o}$ and $f_{g o}$ can be calculated from the single phase friction correlation (Blasius equation) based on liquid Reynolds number, $\left(\operatorname{Re}_{l o}=G d / \mu_{l}\right)$ and gas Reynolds number $\quad\left(\operatorname{Re}_{g o}=G d / \mu_{g}\right)$. From Blasius equation: $f_{l o}=0.079 / \operatorname{Re}_{l o}^{0.25}$ and $f_{g o}=0.079 / \operatorname{Re}_{g o}^{0.25}$.

The pressure drop for assuming the total flow is liquid, $(d p / d x)_{l o}$ can be calculated as,

$$
\left(\frac{d p}{d x}\right)_{l o}=\frac{2 f_{l o} G^{2} v_{l}}{d}
$$

Where $v_{l}$ is the liquid specific volume $\left(\mathrm{m}^{3} / \mathrm{kg}\right)$ is Thus, the two-phase flow pressure gradient can be obtained by substituting the Eqs. (9) and Eq. (10) in Eq. (8).

\subsubsection{Muller-Steinhagen and Heck}

Muller-Steinhagen and Heck (1986) proposed the following two-phase frictional pressure drop correlation based on all liquid flow and all gas flow,

$$
\left(\frac{d p}{d x}\right)_{T F}=G_{M S}(1-x)^{1 / 3}+B x
$$

where the factor $G_{M S}$ is defined as,

$$
G_{M S}=A+2(A-B) x
$$

Assuming the total flow is liquid, the pressure drop $(d p / d x)_{l o}$ can be calculated as: 


$$
A=\left(\frac{d p}{d x}\right)_{l o}=\frac{2 f_{l o} G^{2} v_{l}}{d}
$$

Similarly, the pressure drop for assuming the total flow is gas $\left((d p / d x)_{g o}\right)$ :

$$
B=\left(\frac{d p}{d x}\right)_{g o}=\frac{2 f_{g o} G^{2} v_{g}}{d}
$$

The literature review presented above shows that in spite a number of empirical models developed to predict the pressure drop of multiphase flow, there is still a dearth of research work needed in this area as there are no reliable models that can be used for different geometries and flow patterns. Hence, the purpose of this paper is twofold. The first is to collect new experimental data on pressure drop for various pipe diameters with different flow patterns (Teesside University) at Constant Water Flow rate (CWF) where the air is added to the water. In addition to Constant Total Flow rate (CTF) where the flow rates for both phases are changed to give CTF. The second is to examine the possibility of using the drift-flux model (utilizing the approximate Riemann solver proposed by Santim and Rosa (2015) to predict the pressure drop for two-phase flows by comparing the experimental data with predictions from the model. In addition, the present experimental measurements are also compared with predictions from empirical models in the literature.

\section{Experimental facility}

The experimental facility shown in Figure 1 is designed and built at Teesside University, to investigate the pressure drop for single and two-phase flows pressure drop. The test rig has three PVC transparent pipes of 1 meter in length and inner diameters of $0.0127 \mathrm{~m}, 0.01905 \mathrm{~m}$ and $0.0254 \mathrm{~m}$. The main components of the test rig are the water centrifugal pump, air compressor, water and air flow meters, water tank, and differential pressure transducer. 


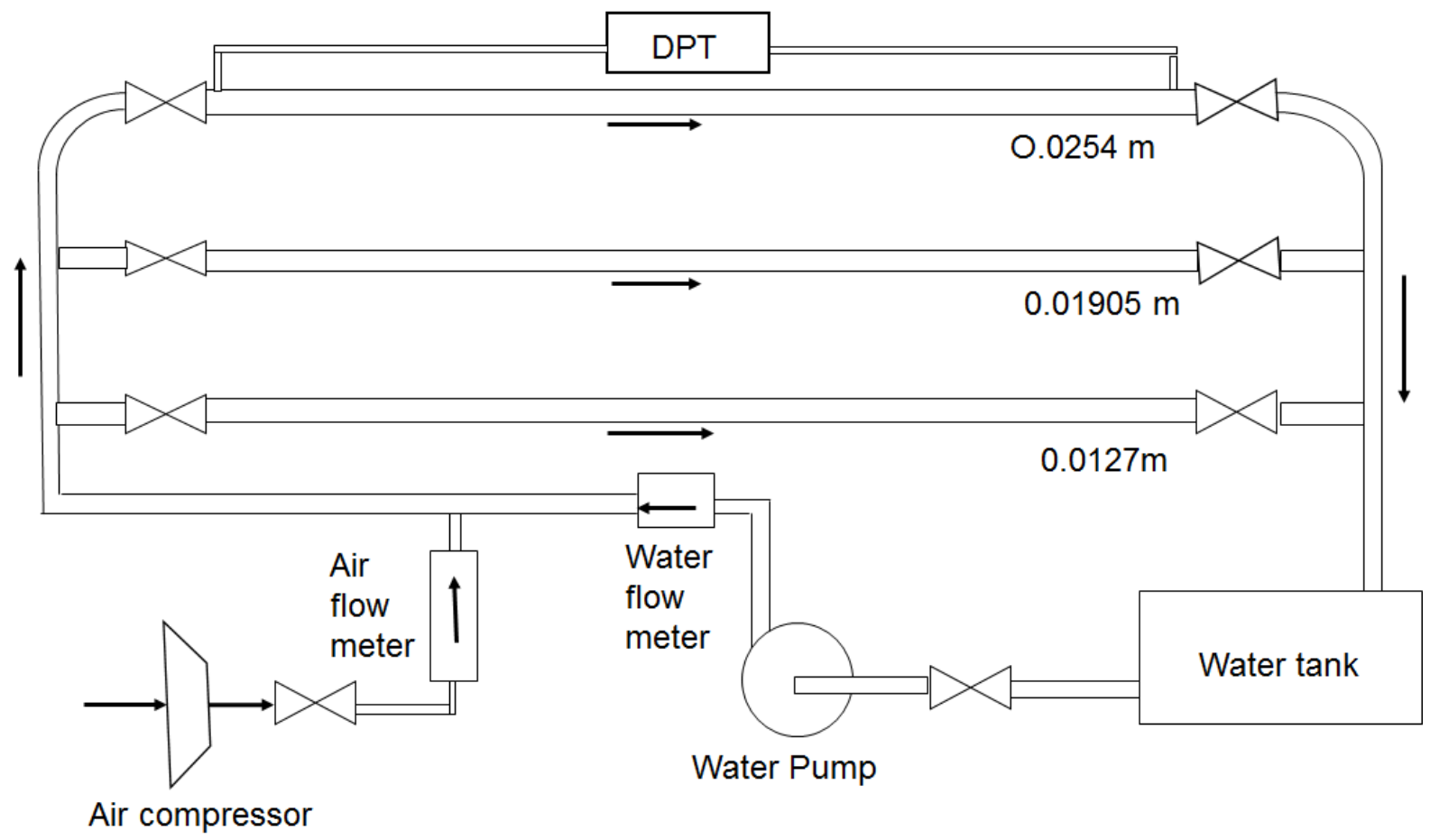

Figure 1. Schematic diagram of the experimental rig.

To generate air-water mixture, the water is pumped from the tank to the test section using a centrifugal pump. Then, the air is supplied from the main compressor in the building via a filter and pressure regulator, this is done to minimise the fluctuation in air flow rate. The air and water flow rates are measured by the flow meters at the upstream of the mixing point.

In this investigation, the measurements are performed under constant water flow rate (CWF) by adding air to the water and constant total flow rate (CTF) in which the flow rates for both phases are changed to give same CTF. The water flow rate up to 40 $\mathrm{I} / \mathrm{min}$ was measured by the digiflow $6710 \mathrm{M}$ meter. The air flow rate was measured by Platon air flow meter with accuracy of $\pm 1.25 \%$. The differential pressure transducer (C9553 COMARK) is connected to the test section by two flexible plastic tubes via two taps at inlet and exit of the pipe. The images of flow patterns are obtained by a high-speed digital camera (NiKon 1J1). Due to the limited length of the pipes, a perforated pate was used a flow conditioned eliminate velocity profile distortion and uneven void fraction distribution. 


\section{Numerical solution}

A Roe-type Riemann solver based on drift-flux model proposed by Santim and Rosa (2015) was used to calculate the pressure drop numerically. The model is assumed to be isothermal with no mass transfer between the phases. The system of equations for the conservation laws is given by Eqs. (15)-(17). The first two equations consist of mass formulations for each phase i.e, liquid and gas and the last equation for the mixture momentum conservation.

$$
\begin{gathered}
\frac{\partial}{\partial t}\left[(1-\alpha) \rho_{l}\right]+\frac{\partial}{\partial x}\left[(1-\alpha) \rho_{l} u_{l}\right]=0, \\
\frac{\partial}{\partial t}\left(\alpha \rho_{g}\right)+\frac{\partial}{\partial x}\left(\alpha \rho_{g} u_{g}\right)=0, \\
\frac{\partial}{\partial t}\left[(1-\alpha) \rho_{l} u_{l}+\alpha \rho_{g} u_{g}\right]+\frac{\partial}{\partial x}\left[(1-\alpha) \rho_{l} u_{l}^{2}+\alpha \rho_{g} u_{g}^{2}+P\right]=F_{W},
\end{gathered}
$$

where $P$ is the pressure, $\alpha$ represents the void fraction, $\rho$ is the density, $u$ is the velocity, with the subscripts $/$ and $g$ refer to the liquid and gas phases. The last term on Eq. (17), $F_{W}$, is a momentum source term that represents the wall friction force and is given as:

$$
F_{W}=f \frac{\rho_{m}\left|u_{m}\right| u_{m}}{2 d}
$$

In which $u_{m}=(1-\alpha) u_{l}+\alpha u_{g}$ represents the mixture velocity, $\rho_{m}=\alpha \rho_{g}+(1-\alpha) \rho_{l}$ is the density of mixture in terms of the void fraction, $f$ represents the friction factor and $d$ is the ID pipe.

The friction factor $(f)$ depends on Reynolds number of the mixture $\left(\operatorname{Re}_{m}\right)$, which is defined as:

$$
\operatorname{Re}_{m}=\frac{\rho_{m}\left|u_{m}\right| d}{\mu_{m}}
$$

where $\mu_{m}$ is the mixture viscosity. The relation proposed by Beattie and Whalley (1982) is used: $\mu_{m}=(1-\alpha) \mu_{l}(1+2.5 \alpha)+\alpha \mu_{g}$ in the range $0<\alpha<1$. 
For laminar flows, the friction factor is defined as $f=64 / \mathrm{Re}_{m}$. The implicit relation proposed by Colebrook, Eq. (21), is utilized to calculate $f$ for turbulent flows since the Eq. (20), proposed by Haaland, is assumed as an initial guess for Colebrook's equation.

$$
\begin{aligned}
& \frac{1}{\sqrt{f}}=-1.8 \log \left(\left(\frac{\varepsilon}{3.7 D}\right)^{1.11}+\frac{6.9}{\operatorname{Re}_{m}}\right), \\
& \frac{1}{\sqrt{f}}=-2 \log \left(\frac{\varepsilon / D}{3.7}+\frac{2.51}{\operatorname{Re}_{m} \sqrt{f}}\right)
\end{aligned}
$$

where $\varepsilon$ represents the equivalent roughness of the pipe, considered as $10^{-9} \mathrm{~m}$.

The thermodynamic state equations for the liquid and gas densities are expressed in terms of the sound velocities, $c_{l}$ and $c_{g}$, as presented below $\rho_{l}=\rho_{l, 0}+\frac{P-P_{l, 0}}{c_{l}^{2}}$ and $\rho_{g}=\frac{P}{c_{g}^{2}}$, where $\rho_{l, 0}$ and $P_{l, 0}$ are given as constants.

The system of the conservation laws, given by Eqs. (15)-(17), can be written in the conservative form, as:

$$
\frac{\partial \mathbf{U}}{\partial t}+\frac{\partial \mathbf{F}}{\partial x}=\mathbf{S},
$$

where $\mathbf{U}, \mathbf{F}$ and $\mathbf{S}$ are the vectors of the conservative variables, fluxes and source terms written as follows:

$$
\mathbf{U}=\left(\begin{array}{c}
U_{1} \\
U_{2} \\
U_{3}
\end{array}\right) \equiv\left(\begin{array}{c}
(1-\alpha) \rho_{l} \\
\alpha \rho_{g} \\
(1-\alpha) \rho_{l} u_{l}+\alpha \rho_{g} u_{g}
\end{array}\right) \mathbf{F}=\left(\begin{array}{l}
F_{1} \\
F_{2} \\
F_{3}
\end{array}\right) \equiv\left(\begin{array}{c}
(1-\alpha) \rho_{l} u_{l} \\
\alpha \rho_{g} u_{g} \\
(1-\alpha) \rho_{l} u_{l}^{2}+\alpha \rho_{g} u_{g}^{2}+P
\end{array}\right) \mathbf{S}=\left(\begin{array}{c}
S_{1} \\
S_{2} \\
S_{3}
\end{array}\right) \equiv\left(\begin{array}{c}
0 \\
0 \\
F_{W}
\end{array}\right) .
$$

Since the system has three equations and four unknowns, we need to obtain the system closure by using of a drift-flux relation. The relation chosen was $u_{g}=C_{0} u_{m}+u_{d}$, presented by Zuber and Findlay (1975). The parameter $C_{0}$ and the drift velocity $u_{d}$ are defined primarily considering the fluid transport properties and sometimes by the flow pattern regime. The drift parameters implemented on the solver were proposed by Choi et al. (2012) and are pattern independent. This correlation was chosen since 
the pipe length is too short or flow to fully develop and achieve a define defined flow pattern.

$$
\begin{gathered}
C_{0}=\frac{2}{1+\left(\frac{\mathrm{Re}_{m}}{1000}\right)^{2}}+\frac{1.2-0.2 \sqrt{\frac{\rho_{g}}{\rho_{l}}}\left(1-e^{-18 \alpha}\right)}{1+\left(\frac{1000}{\mathrm{Re}_{m}}\right)^{2}}, \\
u_{d}=C \cos (\theta)+D\left(\frac{g \sigma \Delta \rho}{\rho_{l}^{2}}\right)^{1 / 4} \sin (\theta) .
\end{gathered}
$$

The discretization scheme used in the simulations is an upwind discretization as demonstrated by Leveque (2002), in which the vector $\mathbf{U}$ of conservative variables has its components $U_{i}$ evaluated using an explicit numerical procedure depicted below:

$$
U_{i}^{n+1}=U_{i}^{n}-\frac{\Delta t}{\Delta x}\left[\sum_{p=1}^{m}\left(\lambda^{p}\right)^{-} \boldsymbol{W}_{i+1 / 2}^{p}+\sum_{p=1}^{m}\left(\lambda^{p}\right)^{+} \boldsymbol{W}_{i-1 / 2}^{p}\right]
$$

in which,

$$
\boldsymbol{\beta}_{i-1 / 2}=\mathbf{R}^{-1}\left(\mathbf{U}_{i}-\mathbf{U}_{i-1}\right) \text { and } \mathcal{W}_{i-1 / 2}^{p}=\beta_{i-1 / 2}^{p} r^{p},
$$

where $W$ represents the waves crossing the cells' interface, $\lambda^{-}$and $\lambda^{+}$are the characteristic velocities (superscript '-' means left going waves). The matrix $\mathbf{R}$ represents the right eigenvector matrix, and $p$ is the counter of eigenvalues ( $m$ is the total number).

This explicit scheme must satisfy a CFL (Courant-Friedrichs-Lewy) condition as stability criterion:

$$
\left|\lambda_{\max }\right| \frac{\Delta t}{\Delta x}<1
$$

The wall friction force source term is treated using the Fractional-Step method studied by Leveque (2002). The hyperbolic system is split into two sub-problems which are solved independently. The first consists of a homogeneous system using the upwind scheme previously presented in Eq. (26). 


$$
U_{i}^{*}=U_{i}^{n}-\frac{\Delta t}{\Delta x}\left[\sum_{p=1}^{m}\left(\lambda^{p}\right)^{-} \boldsymbol{W}_{i+1 / 2}^{p}+\sum_{p=1}^{m}\left(\lambda^{p}\right)^{+} \boldsymbol{W}_{i-1 / 2}^{p}\right]
$$

The ODE must be solved in a second step, as

$$
U_{i}^{n+1}=U_{i}^{*}-\Delta t S_{3}
$$

To obtain a numerical solution on pressure drop along a pipe, a spatial mesh with 100 nodal points is chosen after a mesh test, and a temporal mesh with 20000 points is used. Finally, the transient simulation is halted to record the results when it reaches the steady state.

\section{Results and discussion}

\subsection{Single phase pressure gradient}

The single-phase flow measurements are carried out to validate the experimental facility along with the accuracy of instrumentation and thereby set the reference velocities to be used for the comparison with two-phase flow measurements. The pressure drop data for different water flow rates is recorded and this is used to calculate the friction factor by applying Darcy equation for smooth pipe as:

$$
f_{\exp }=\frac{\Delta p d}{2 L \rho v^{2}} \text {. }
$$

Figure 2 presents the comparison of the experimental friction factor $f_{\text {exp }}$ with predicted values from Blasius correlation $\left(f=0.079 / \mathrm{Re}^{0.25}\right)$ for each flow rate $(\mathrm{Re})$. The error associated with the pressure drop measurements proves to be quite reasonable $( \pm 10 \%)$. The discrepancy in the data compared to well-known correlation developed by Blasius may attributed to the inaccuracy of flow meters and pressure transducer and the change in temperature due the heat added by the pump. The temperature affects the density and viscosity of the fluid used in calculation of Renolds number used in calculation of friction factor. 


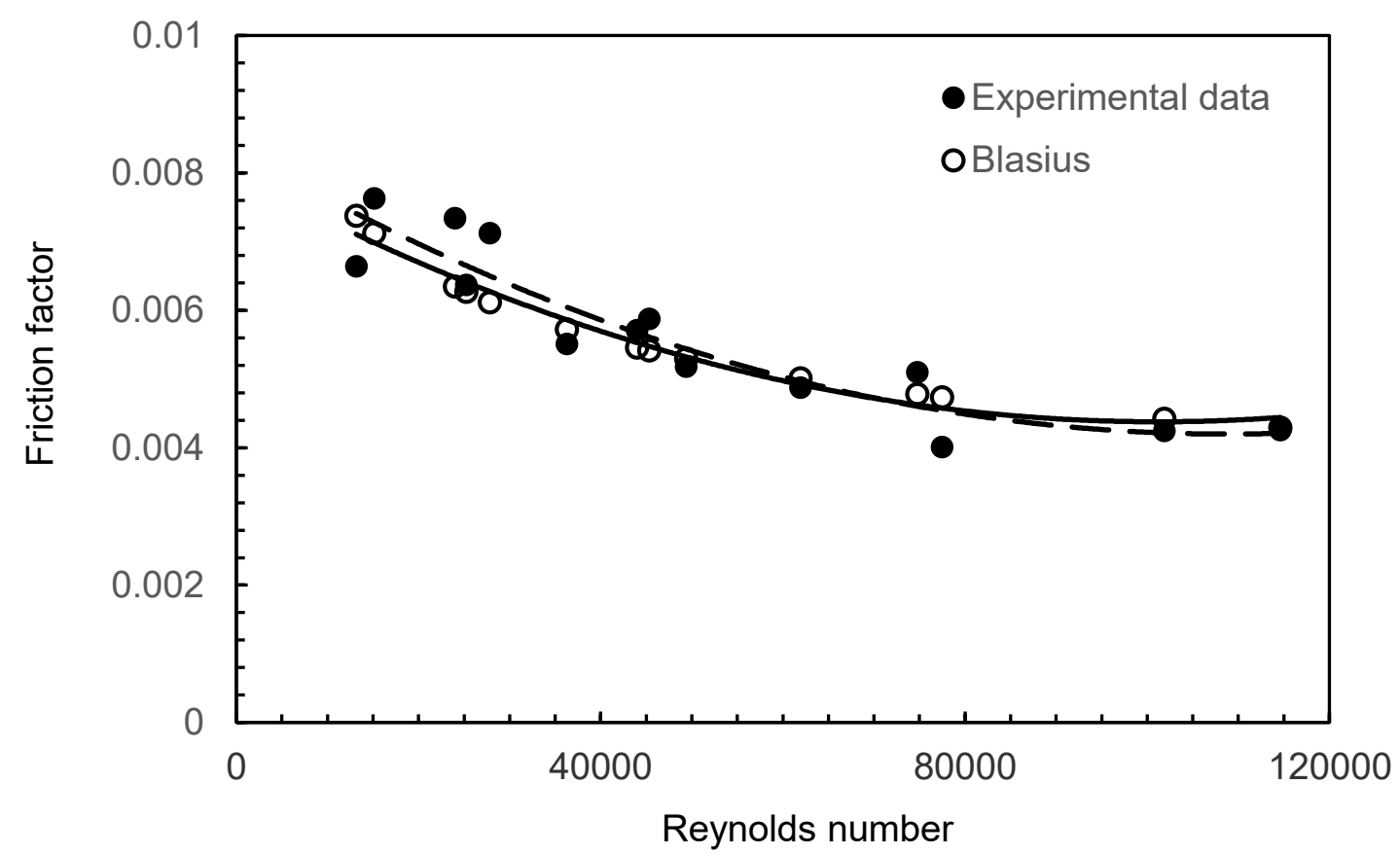

Figure 2. Comparision of measured single phase flow friction factor with prediction from Blasius correlation.

\subsection{Two-phase flow measurements}

The frictional pressure drop in this study was investigated with two different methods of two-phase generation. In the first method, air is injected while the water flow rate kept is constant, hence that increases the total mass flow rate and $\beta$ of mixture. This method is called Constant Water Flow (CWF). In the second method, the total flow rate of the mixture is kept constant and the flow rate is changed for both the phases, this leads to a two-phase flow. This method is called Constant Total Flow rate (CTF). For $C W F$, the results show that the increase in $\beta$ lead to an increase in the mixture mass flux and the pressure drop. This is a similar trend that was observed by MullerSteinhagen and Heck (1986), Shannak (2008) and Hamayun et al. (2010). In contrast to the CWF cases, the results show that an increase in $\beta$ lead to a reduction in mass velocity and pressure drop. The measured pressure drop for CWF and CTF are presented in Figures $3 \mathrm{a}, 3 \mathrm{~b}$ and $3 \mathrm{c}$, relative to the $0.0254 \mathrm{~m}, 0.01905 \mathrm{~m}$ and $0.0127 \mathrm{~m}$ ID, respectively. 


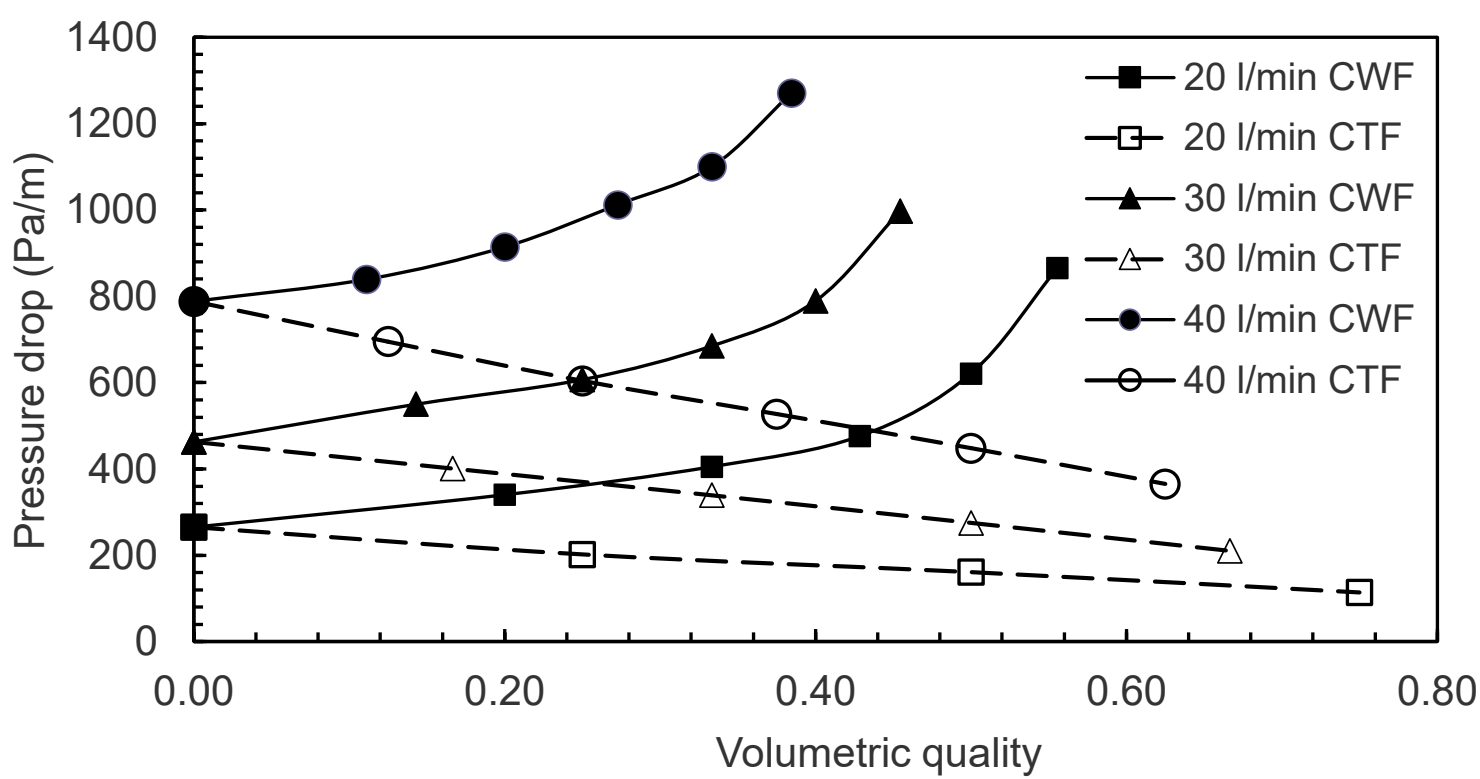

Figure 3a. Variation of measured pressure drop for the CWF and CTF rates in in $0.0254 \mathrm{~m}$ pipe with volumetric quality.

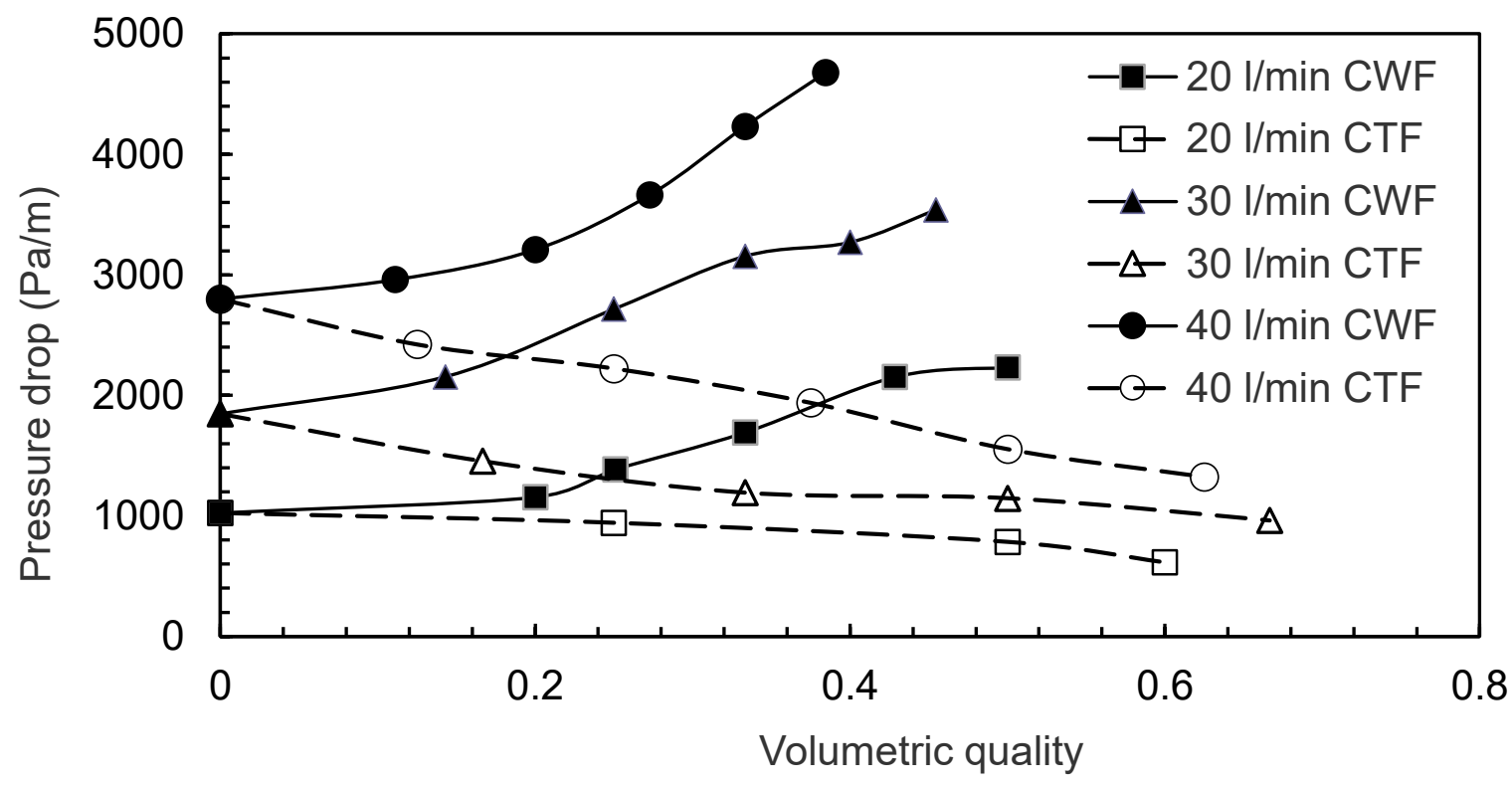

Figure 3b. Variation of measured pressure drop for the CWF and CTF rates in $0.01905 \mathrm{~m}$ pipe with volumetric quality. 


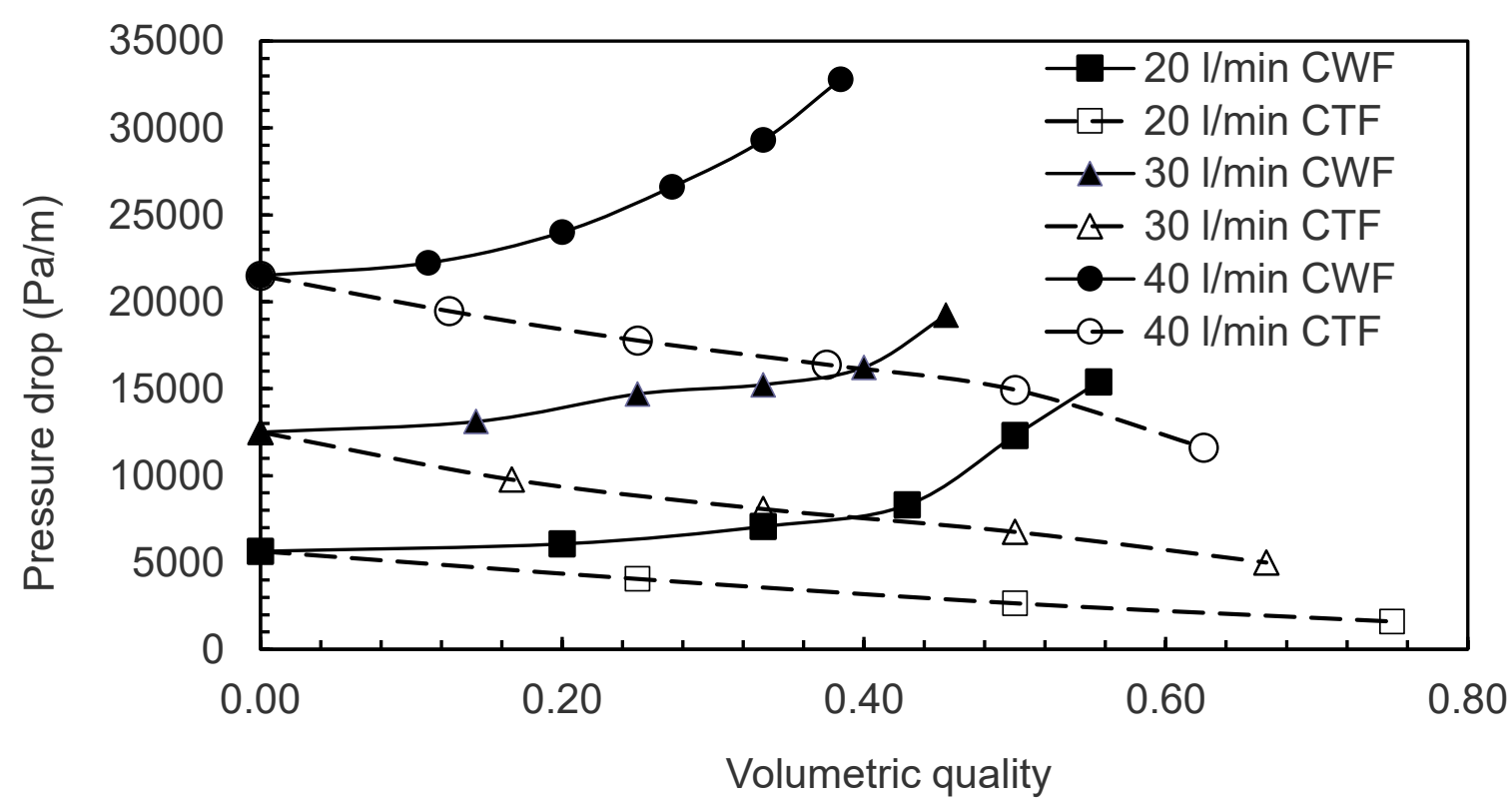

Figure 3c. Variation of measured pressure drop for the CWF and CTF rates in $0.0127 \mathrm{~m}$ pipe with volumetric quality.

The results show that the pressure drop increased significantly for small pipe diameter. To have a better understanding of this effect, the variation of pressure drop with volume fraction for the same water Reynolds number $(R e=26000)$ considering three pipes is given in Fig. 3d. The results show that reducing pipe diameter lead to nonlinear increase in friction pressure drop similar to single phase flow which can be approximated by the following formula: $\Delta p=4.733 \mathrm{~d}^{-1.45}$, this formula is given by Bhagwat et al (2012). A similar finding was reported by Kaji and Azzopardi (2010) for air-water flow in vertical pipes of diameters in a range of $0.010 \mathrm{~m}-0.050 \mathrm{~m}$. 


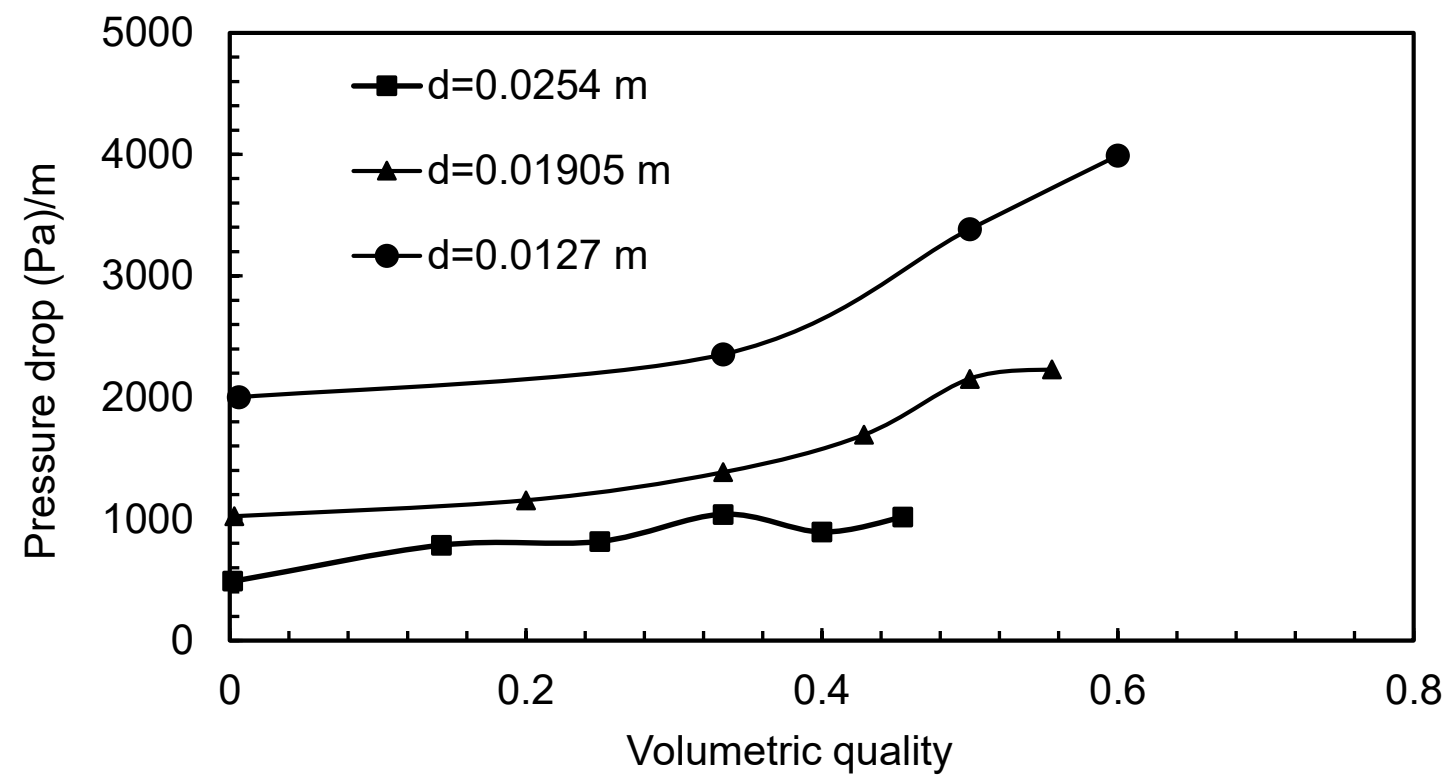

Figure 3d. Effect of pipe diameter on pressure drop $(\operatorname{Re}=26000)$.

\subsubsection{Pressure drop and flow pattern}

From the visual observation of the flow pattern during the pressure drop tests, it is possible to verify that the flow pattern in the pipe is changed. To investigate this in further detail, the water single phase flow of $40 \mathrm{l} / \mathrm{min}$ in $0.0254 \mathrm{~m}$ diameter is selected to observe and the flow pattern for both CWF and CTF at different volumetric qualities. Figure $4 \mathrm{a}$ shows the pressure variation for the vomumetric qualities under investigation. 


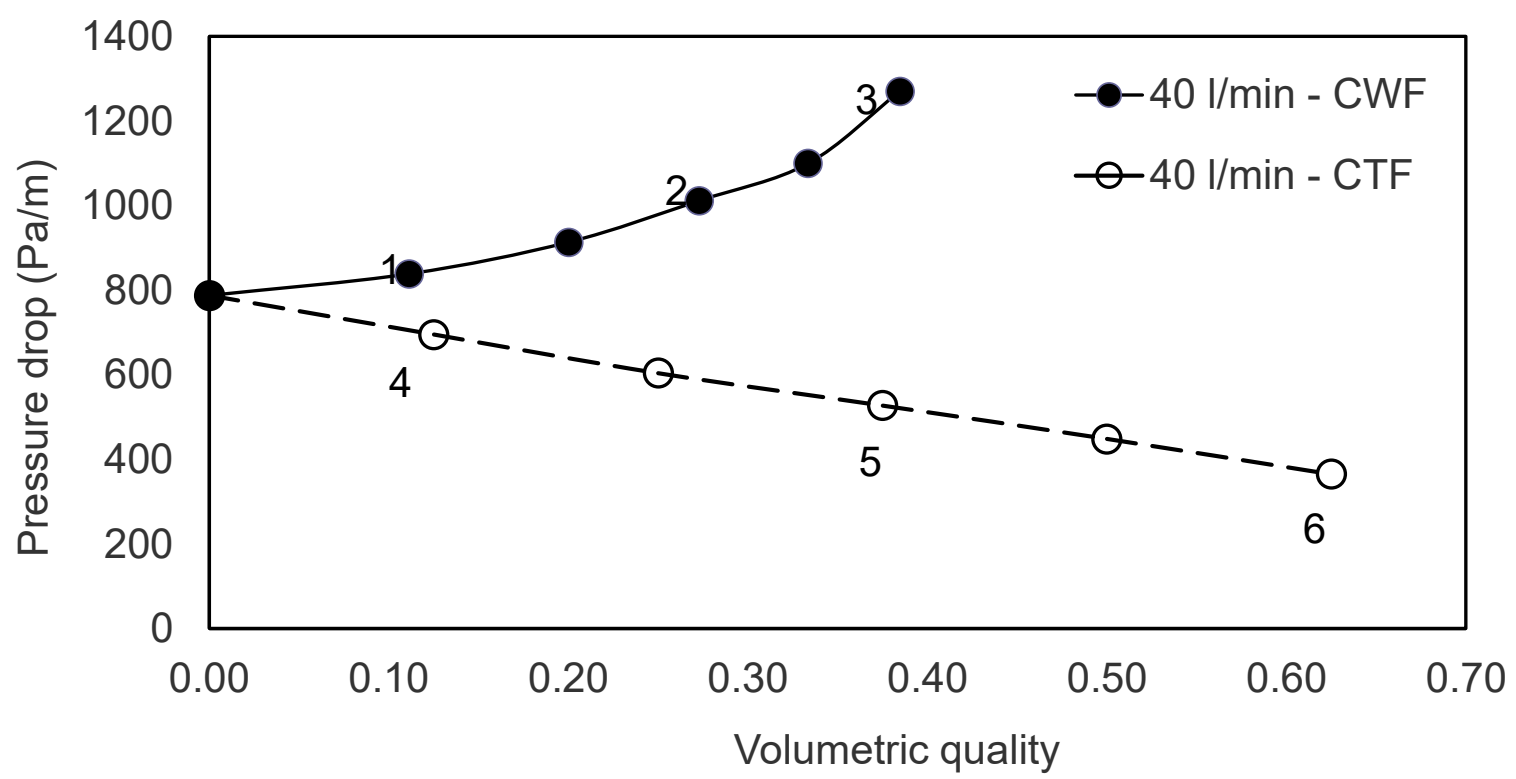

Figure 4a. Variation of the pressure drop with CWF and CTF in the pipe of $0.0254 \mathrm{~m}$. (Water flow rate $=40 \mathrm{l} / \mathrm{min}$ ).

The corresponding flow pattern at points 1, 2, 3, 4, 5 and 6 are given in Figures $4 \mathrm{~b}$ and 4c. The flow patterns are observed visually and recorded photographically using High Speed Camera for water flow rate of $40 \mathrm{l} / \mathrm{min}$ in $0.0254 \mathrm{~m}$ ID pipe. For CWF cases (Figure $4 b$ ), the photos show that two different zones of bubbly flow and water can be observed. For lower air flow rate of $5 \mathrm{l} / \mathrm{min}(\beta=11.1 \%)$, bubbly flow of $1 \mathrm{~cm}$ height is formed in the upper part of the pipe while water zone of $1.5 \mathrm{~cm}$ height flow in the rest of the pipe separated by wavy interface. The thickness of the bubbly flow zone expand further down to become $1.5 \mathrm{~cm}$ for air flow of $15 \mathrm{l} / \mathrm{min}(\beta=27.3 \%)$ and $2 \mathrm{~cm}$ for air flow rate of $25 \mathrm{l} / \mathrm{min}(\beta=38.5 \%)$. The large long bubbles appears near the upper pipe wall at the upper region of the bubbly flow zone for $\beta=38.5 \%$.

For the CTF, the photos show that by replacing $5 \mathrm{l} / \mathrm{min}(12.5 \%)$ of water with air, generates two layers of the flow similar to flow pattern at point 1 for CWF. Increasing the air to $15 \mathrm{l} / \mathrm{min}(\beta=37.5 \%)$ leads to an appearance of air of about $0.6 \mathrm{~cm}$ thickness at the top, water layer at the bottom of the pipe and this bottom layer is separated by a middle layer of bubbly flow. The bubbly flow lies in the central region of the pipe. The flow in the middle layer is very chaotic and has unstable wavy interface with air and water. A similar flow pattern is observed for higher air flow rate 
of $25 \mathrm{I} / \mathrm{min}(\beta=62.5 \%)$, but the layer of air becomes thicker and water layer becomes thinner.

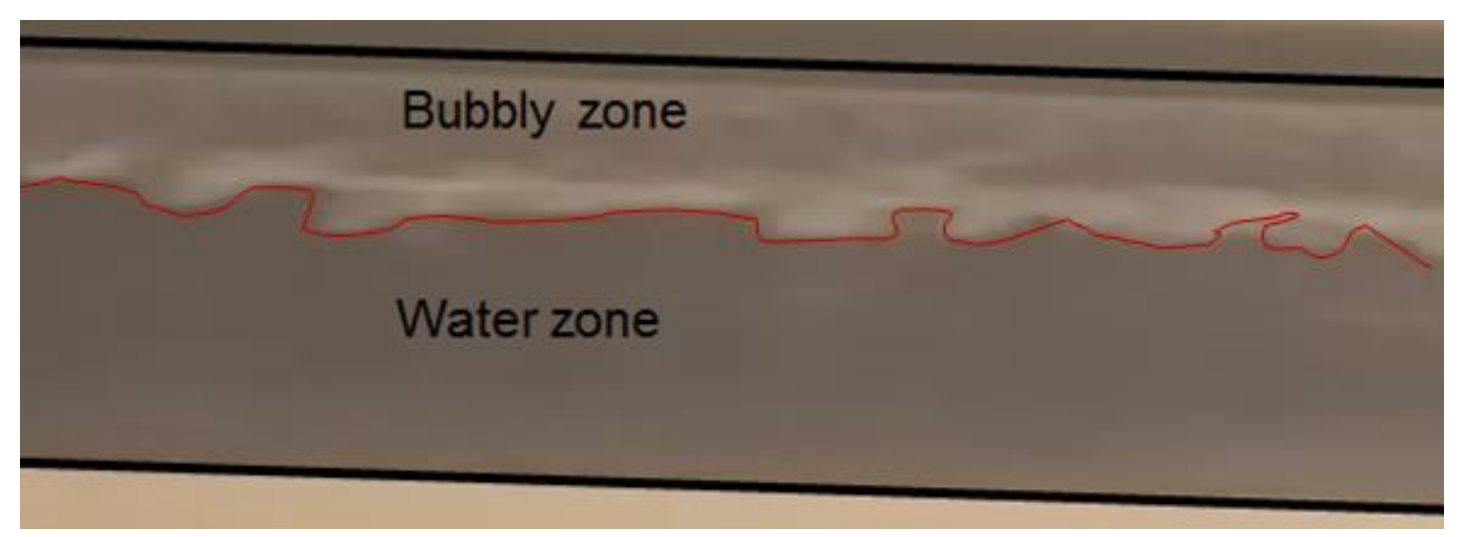

1) $C W F, \beta=0.11, \Delta p=839 \mathrm{~Pa} / \mathrm{m}$

\section{Bubbly Zone}

\section{Water zone}

2) $C W F, \beta=0.272, \Delta p=1012 \mathrm{~Pa} / \mathrm{m}$

\section{Bubble zone}

\section{Water zone}

3) $C W F, \beta=0.385, \Delta p=1271 \mathrm{~Pa} / \mathrm{m}$

Figure 4b: Photographs of CWF cases $(d=0.0254 \mathrm{~m}, 401 / \mathrm{min})$ 


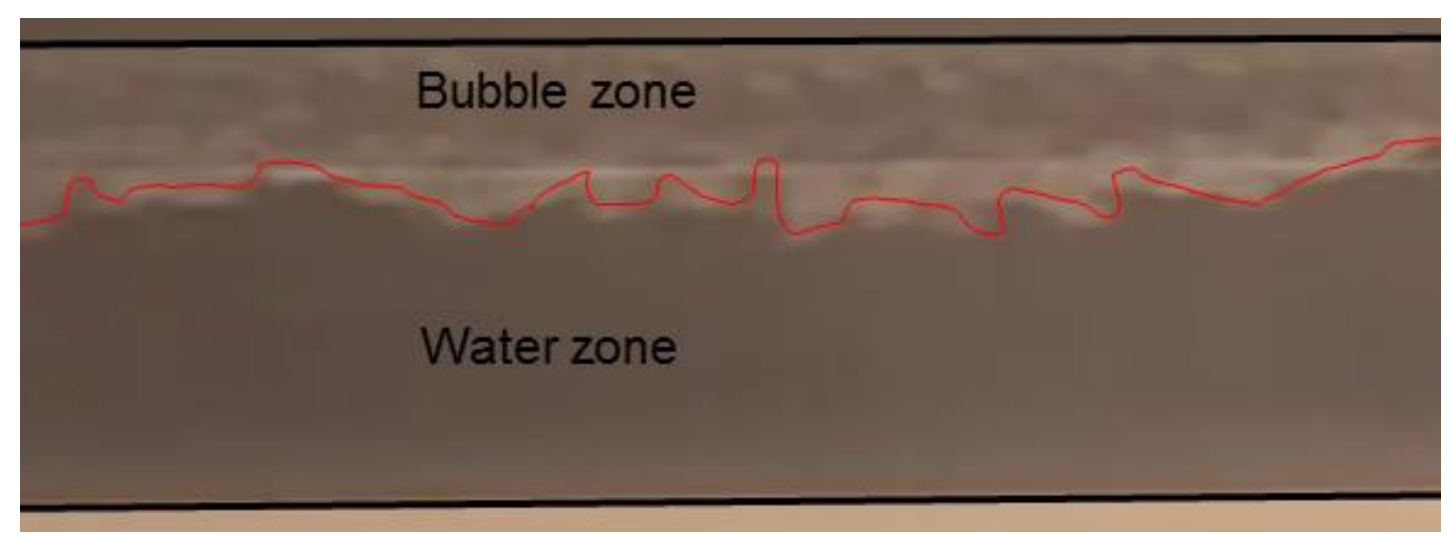

4) CTF, $\beta=0.125, \Delta \mathrm{p}=695 \mathrm{~Pa} / \mathrm{m}$

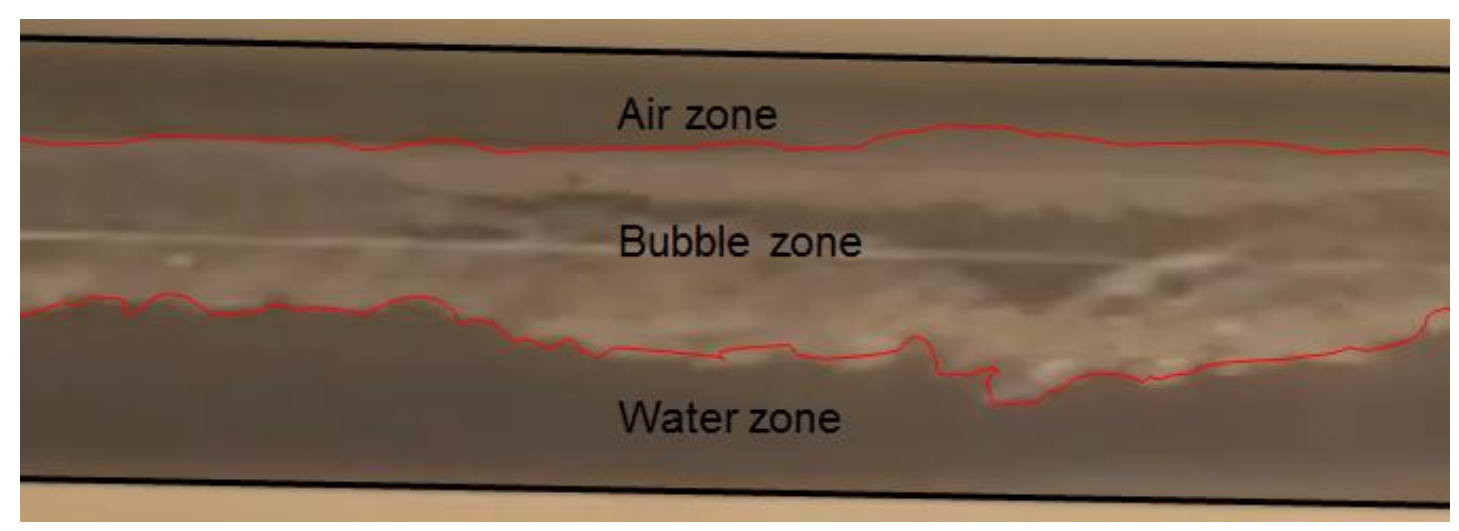

5) CTF, $\beta=0.375, \Delta p=527 \mathrm{~Pa} / \mathrm{m}$

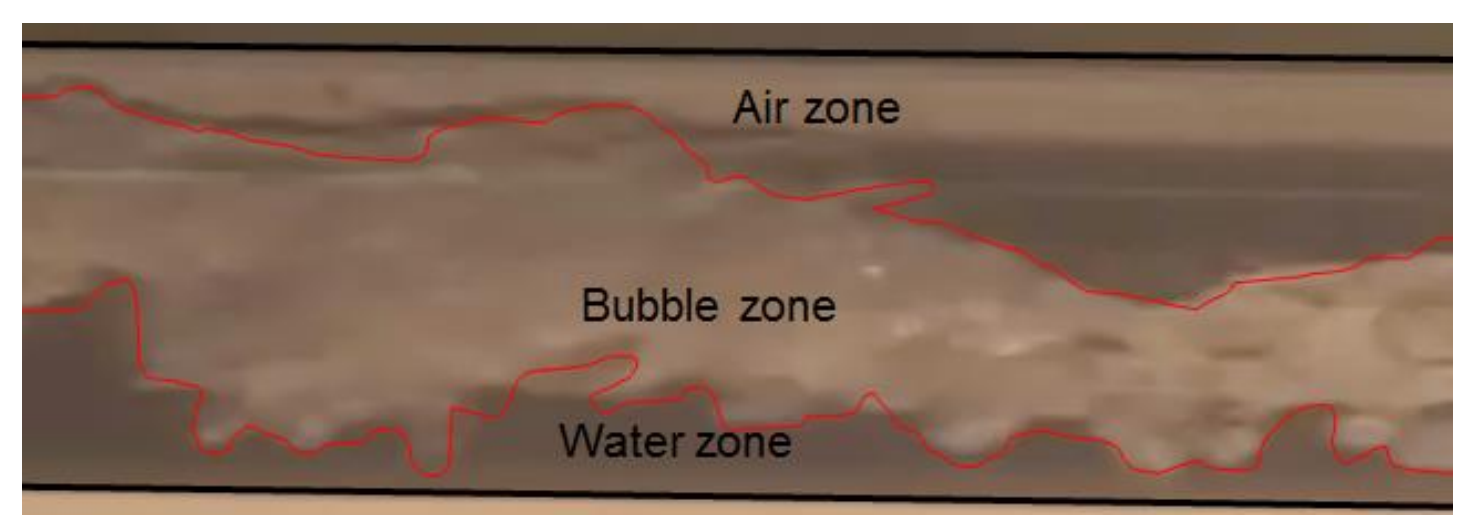

6) CTF, $\beta=0.625, \Delta p=365 \mathrm{~Pa} / \mathrm{m}$

Figure 4c: Photographs of CWF (d =0.0254m, $40 \mathrm{l} / \mathrm{min})$.

The changes in volumetric quality $(\beta)$, flow structure and pressure drop in photos of Figures $4 b \& 4 c$ indicate the strong correlation between the pressure drop and the 
flow structure. The pressure drop is a result of energy dissipation, eddy viscosity and bubble induced turbulence. Energy dissipation occurs due to the fluid viscosity and eddy viscosity occurs due the wall generated turbulence. In case of two-phase flow, the turbulence becomes more complicated due to: i) the interaction between the drop-induced turbulence (bubble motion) and shear-induced turbulence (the external force due to main flow). ii) The modification of water radial velocity distribution due to the radial distribution of bubble slip velocity, bubble diameter and volume fraction. To add to this, the introduction of bubble can either enhance or attenuate the liquid turbulence (Serizawa and Kataoka (1990); Hamad and Ganesan (2015).

The modification in energy dissipation (pressure drop) may be attributed to (Hamad and Ganesan (2015): i) the breakup of large scale eddies containing higher energy by the bubble moving faster than water. ii) The drop wake turbulence due the slip velocity between the drops and the continuous phase in bubbly layers generate additional turbulence as described by Risso et al (2008). iii) The unstable fluctuating interface zone between the layers can be considered as an addition wall due to the velocity difference between the two layers which lead to generation of addition eddies.

\subsubsection{Experimental Uncertainties}

The experimental uncertainty is a combined effect of pipe dimensions (length and diameter and surface roughness), the accuracy of instrumentation (flow meters and pressure transducer), the fluid properties (density, viscosity and surface tension) and the operating conditions (flow rate and temperature). The effect of these variables will lead to some error in pressure drop measurements. The error can be estimated using the available statistical correlation and incorporated into the plotted graph as error bars. Figure $4 \mathrm{~d}$ present the experimental data for two-phase flow with error bar. The height of the bars reflects the level of uncertainty at the different Reynolds numbers. It can be observed that the uncertainty is peaked for $R e$ in the rage of $75000-125000$ reflecting the high instability of the flow this 


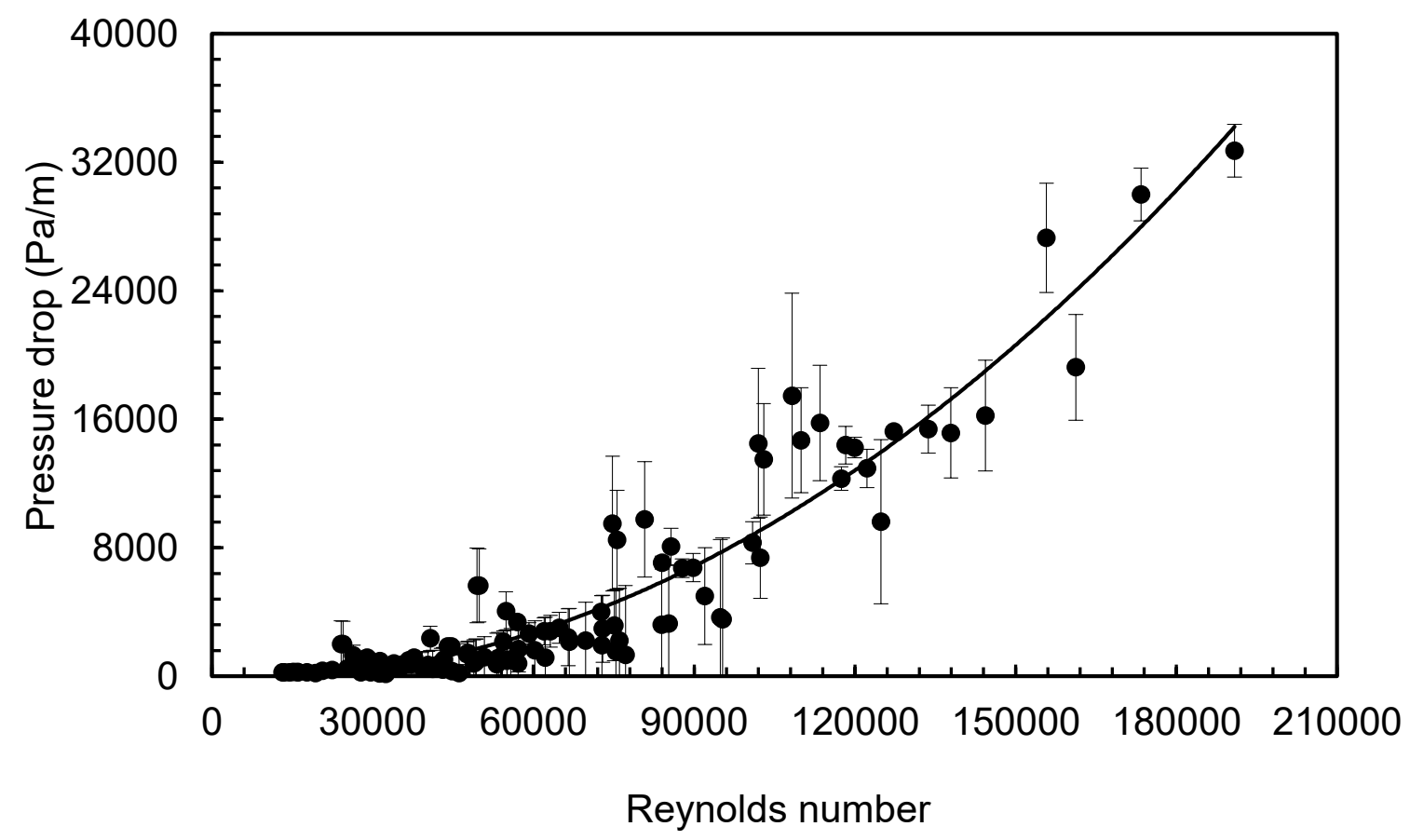

Figure 4d. Experimental data for pressure drop with error bars

\subsection{The Drift-Flux model}

The model takes into account the effects of non-uniform velocity and void fraction profiles as well as effect of local relative velocity between the phases (Shen et al. 2014). The relative motion between the phases is governed by a subset of the parameters inherent to the flow. The model comes from the Two-Fluid model (TFM) through neglecting the static head terms and assuming the momentum conservation of the mixture. Therefore, a third boundary condition is not necessary at the inlet region and the interfacial friction term is cancelled out. Other advantage is that the equations can be put in a conservative form, facilitating to discretize by finite volume methods. The system of the conservation laws is generally hyperbolic depending on the slip law used.

The approximate Roe-type Riemann solver proposed by Santim and Rosa (2015), which is based on the Drift-Flux model, is applied to predict the pressure drop. For all simulations the system shows to be hyperbolic.

Figure 5 represents a comparison between the experimental pressure drop and the numerical prediction as a function of the mixture Reynolds number. The results show that there are different representative zones: i) for $0<\operatorname{Re}<75000$, the data is not 
scattered, ii) for $75000<\operatorname{Re}<125000$, there is a high scatter and iii) Re 125000 the pressure drop increases smoothly. These three zones are similar to laminar, transition and turbulent flow for single phase flow. The comparison proves that the drift-flux model can be used for pressure drop prediction of two-phase flows.

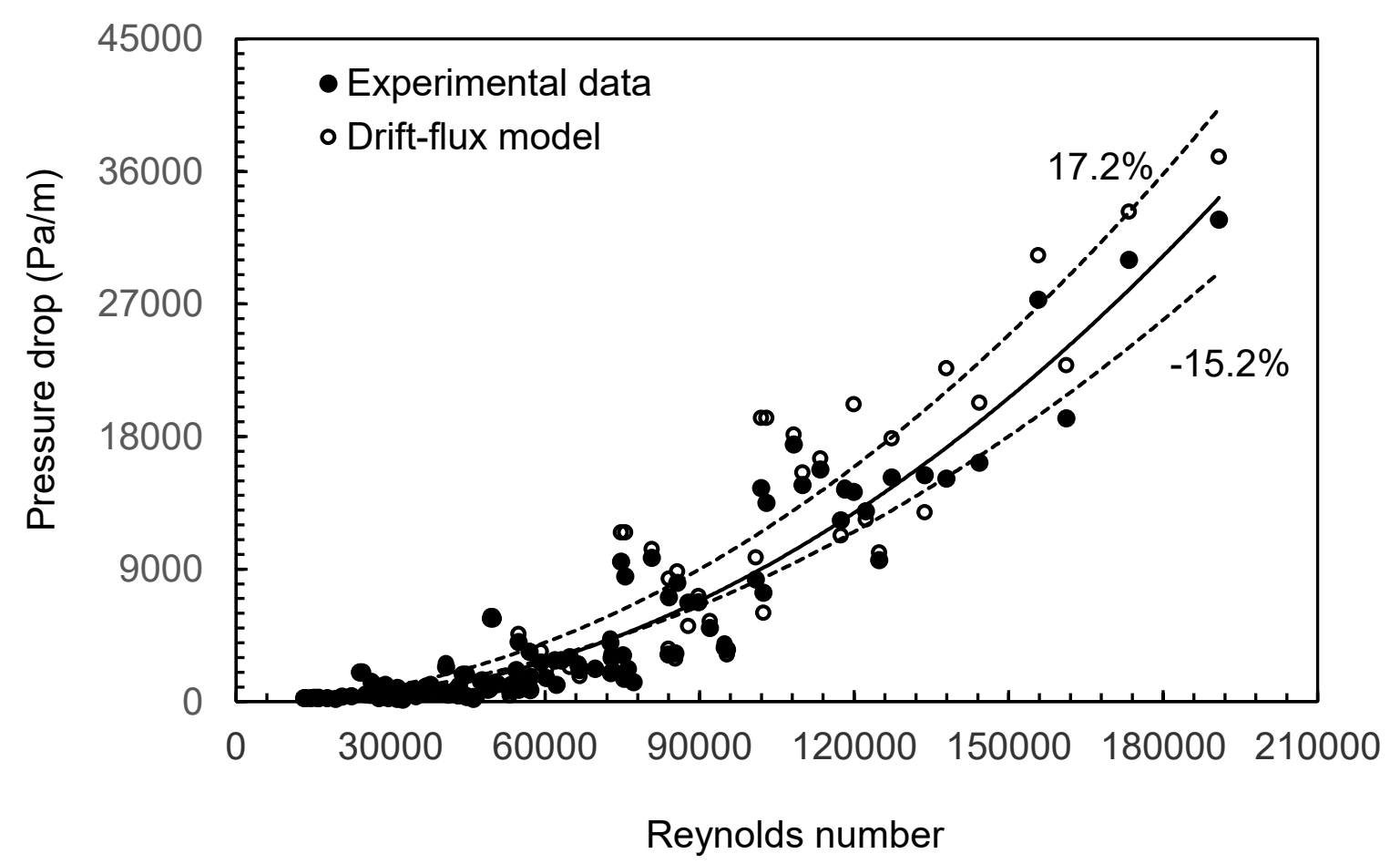

Figure. 5. Comparision between the experimental data and prediction from drifit flux model.

\subsection{Comparison of present pressure drop data with empirical models}

The investigation was carried out for three horizontal pipes of different diameters using air-water mixture. Table 2 provides the range of various parameters used in the experiments. 
Table 2. Experimental measurements

\begin{tabular}{|c|c|c|c|c|c|c|c|c|c|c|c|c|}
\hline \multirow{2}{*}{$\begin{array}{c}\text { Pipe } \\
\text { ID (m) }\end{array}$} & \multirow{2}{*}{$\begin{array}{l}\text { No } \\
\text { of } \\
\text { tests }\end{array}$} & \multirow[t]{2}{*}{$\begin{array}{l}\text { Flow } \\
\text { Type }\end{array}$} & \multicolumn{2}{|c|}{$\mathrm{U}_{\mathrm{sw}}(\mathrm{m} / \mathrm{s})$} & \multicolumn{2}{|c|}{$\mathrm{U}_{\mathrm{sa}}(\mathrm{m} / \mathrm{s})$} & \multicolumn{2}{|c|}{$\beta(\%)$} & \multicolumn{2}{|c|}{$\Delta \mathrm{p}(\mathrm{Pa})$} & \multicolumn{2}{|c|}{$\operatorname{Re}_{m}$} \\
\hline & & & $\min$ & $\max$ & $\min$ & $\max$ & $\min$ & $\max$ & $\min$ & $\max$ & $\min$ & $\max$ \\
\hline 0.0254 & 19 & CWF & 0.66 & & & 0. & & 55 & 60 & 0 & 0 & 00 \\
\hline 0.02 & 14 & CTF & 0. & 1.3 & & 0 & & 1 & 160 & 75 & & 0 \\
\hline & 24 & WT & $\underline{5}$ & & & & & & & & & \\
\hline 0.01 & 20 & CTF & 0.29 & 2.33 & 0 & 1.4 & & 8 & 240 & 28 & 13 & 77000 \\
\hline & 24 & CWF & 1.2 & 3.4 & 0 & & 0 & 71 & 50 & & & \\
\hline 0.01 & 19 & CTF & 0.65 & 5.26 & 0 & 28 & 0 & 83 & 1200 & 21000 & 24000 & 125000 \\
\hline
\end{tabular}

The measured pressure drop values have been compared with the predictions from the most common existing empirical models, the models selected for this purpose are Lockhart and Martinelli (1949), Friedel (1979), Müller-Steinhagen and Heck (1986), Awad \& Muzychka, (2008) and the homogeneous model. The most of the above-mentioned models are applicable for smooth pipes. Therefore, the test conditions of the present experimental data in transparent acrylic pipes are applied to the above-mentioned models. The comparison between the measurements and the predictions are presented in Figures 6, 7, 8 and 9.

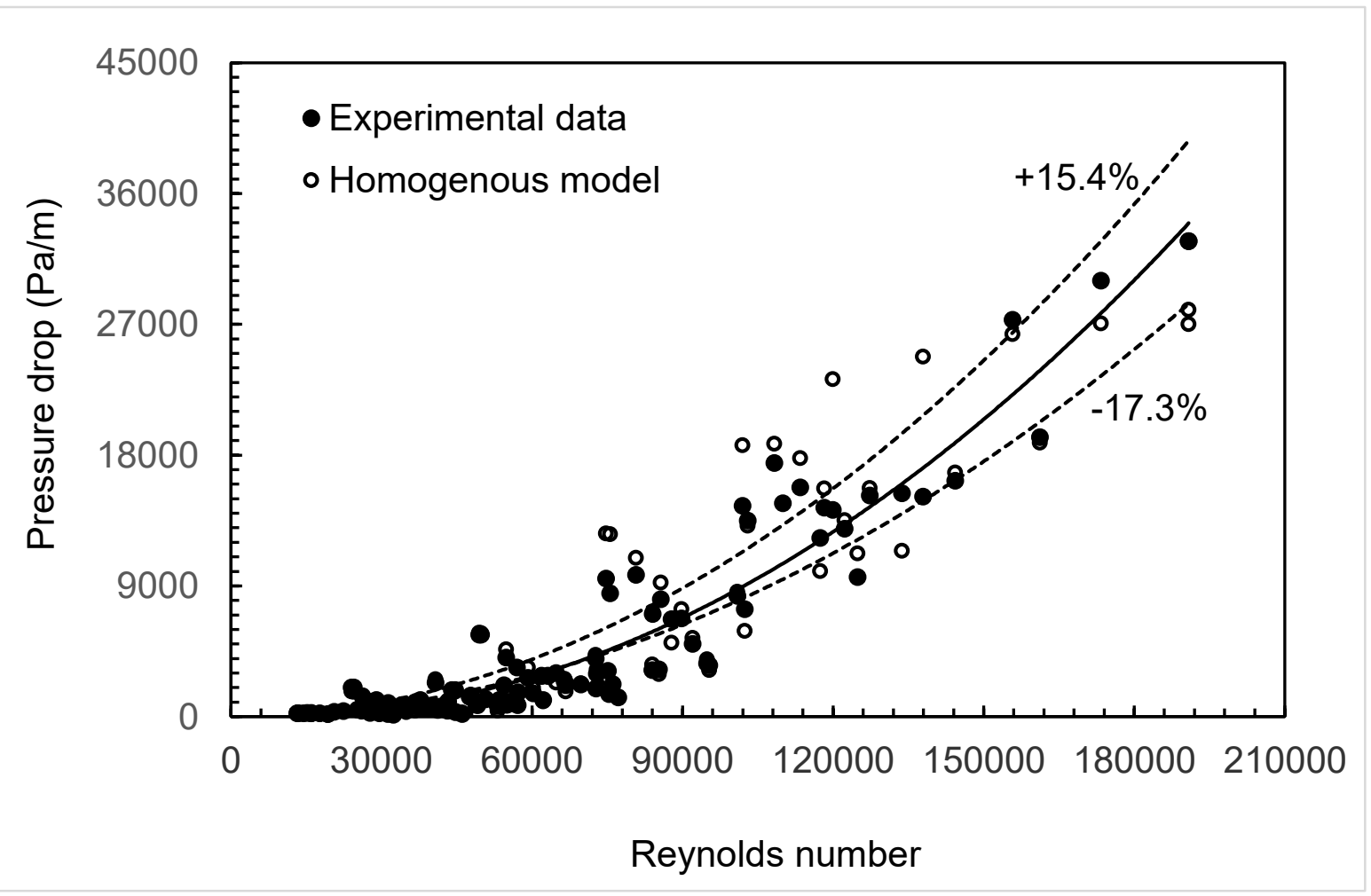

Figure 6a. Comparison of experimental data with Homogenous model. 


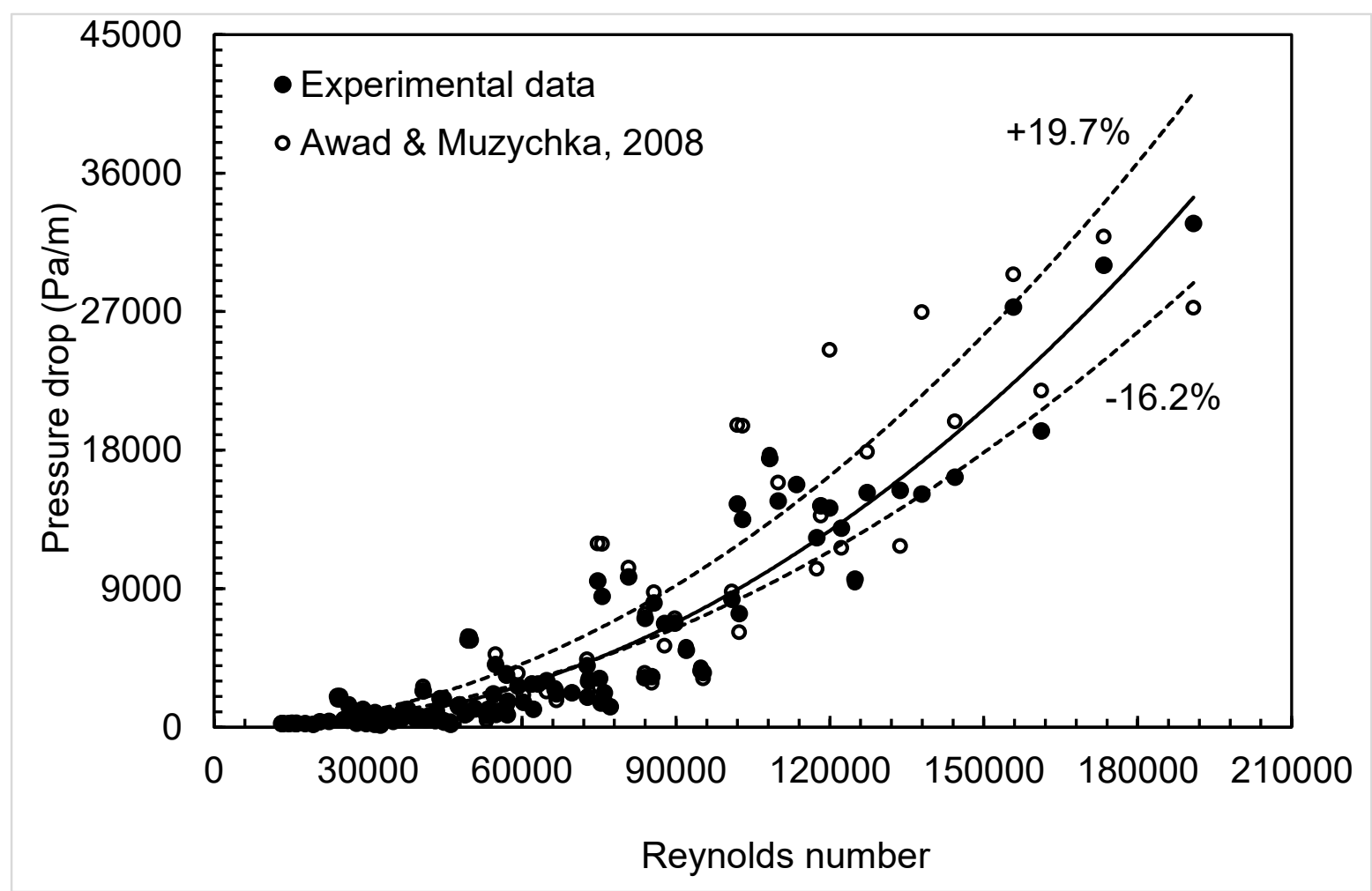

Figure 6b. Comparison of experimental data with Awad \& Muzychka, 2008

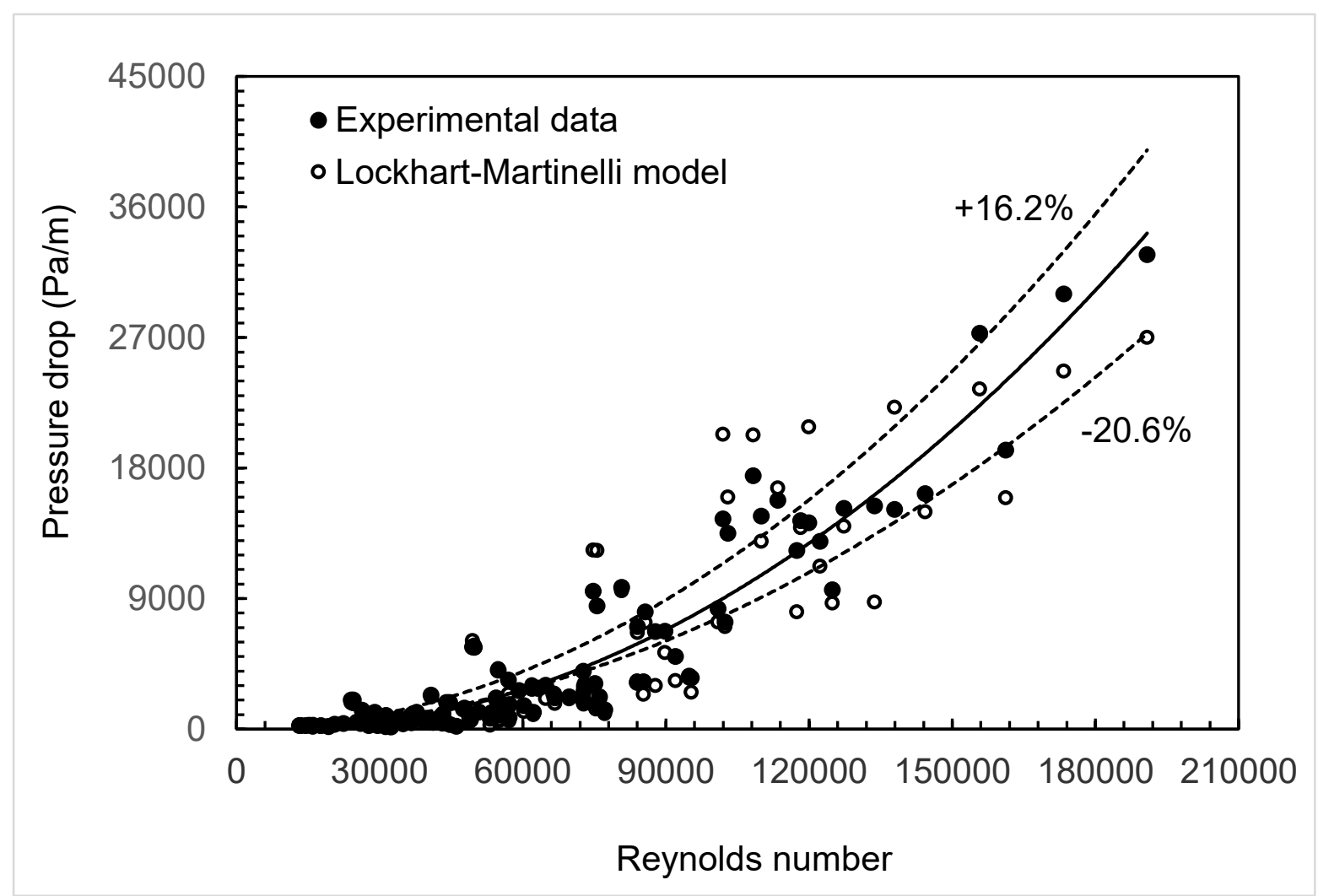

Figure 7. Comparison of experimental data with Lockhart-Martinelli model. 


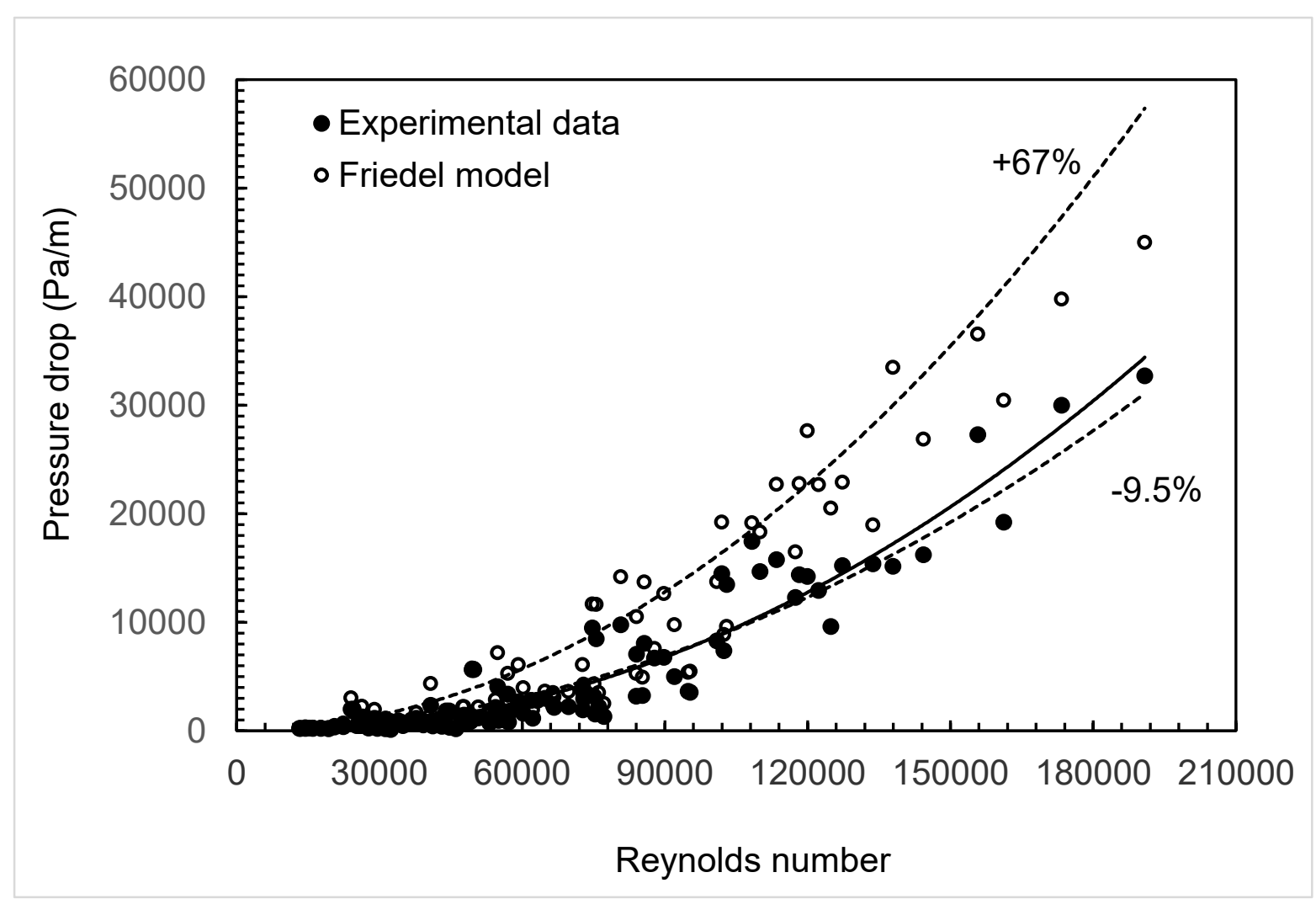

Figure 8. Comparison of experimental data with Friedel model. 


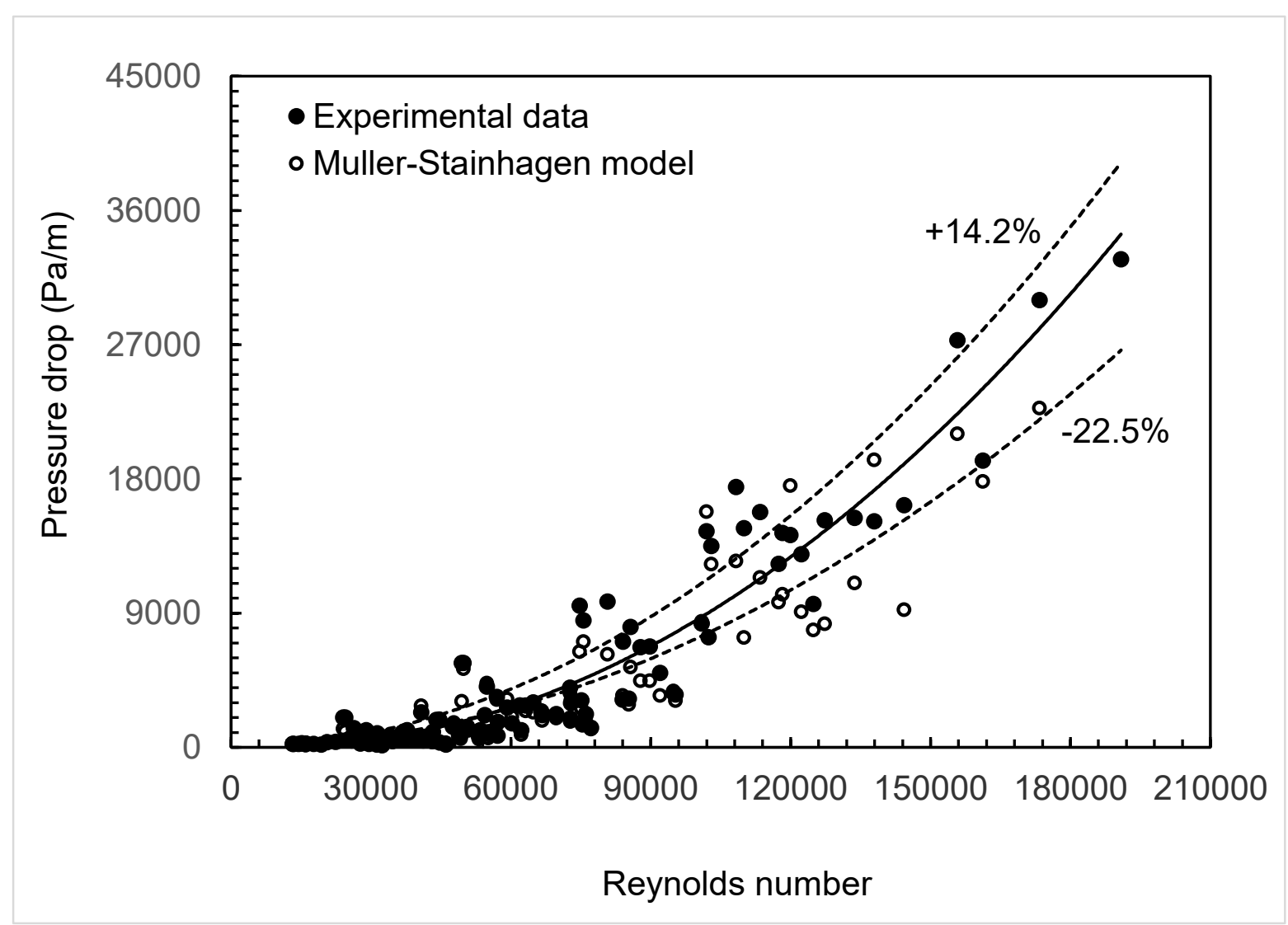

Figure 9. Comparison of experimental data with Muller-Stainhagen model.

The accuracy of the predictions can be measured by calculating the average percent error (APE) and average absolute percent error (AAPE) of each data source.

The percentage error at each point $(\mathrm{PE})$ can be calculated as:

$$
P E=\left[\frac{(d p / d x)_{p r e d}-(d p / d x)_{\exp }}{(d p / d x)_{\exp }}\right] 100
$$

The average percentage error is defined as follows:

$$
A P E=\left\{\frac{1}{n} \sum_{k=1}^{n}\left[\frac{(d p / d x)_{p r e d}-(d p / d x)_{\exp }}{(d p / d x)_{\exp }}\right]\right\} 100 .
$$

Equations (32) and (33) are used to estimate the error of individual points and average error of the data. The average abolute percentage error (AAPE) is calculated to evaluate the prediction capability of the emprical correlation. Unlike the average percent error (APE), the absolute errors are considered so that the positive 
and negative errors are taken into account (the positive and negative errors are not cancelled out). The equation is given as:

$$
A A P E=\left[\frac{1}{n} \sum_{k=1}^{n}\left[\left(\frac{(d p / d x)_{p r e d}-(d p / d x)_{\exp }}{(d p / d x)_{\exp }}\right)^{2}\right]^{1 / 2}\right] 100 .
$$

A summary of the error percentage calculated from Eqs. (33) and (34) for all the models (empiricals and numerical) is given in Table 3.

Table 3.

\begin{tabular}{|c|c|c|c|c|}
\hline Model & APE (\%) & APE (-Ve\%) & APE (+Ve\%) & AAPE (\%) \\
\hline Drift-flux model & 3 & -15.2 & 17.2 & 16.2 \\
\hline Homogenous & --1.9 & -17.3 & 15.4 & 16.2 \\
\hline $\begin{array}{c}\text { Awad \& Muzychka, } \\
(2008)\end{array}$ & 2.8 & -16.2 & 19.7 & 18 \\
\hline $\begin{array}{c}\text { Lockhart-Martinelli } \\
(1949)\end{array}$ & -10 & -21 & 16.2 & 10 \\
\hline $\begin{array}{c}\text { The Friedel } \\
\text { Correlation (1979) }\end{array}$ & 56 & -9.5 & 67 & 60.7 \\
\hline $\begin{array}{c}\text { Muller-Steinhagen } \\
\text { and Heck (1986) }\end{array}$ & -12.2 & -22.5 & 14.2 & 18.6 \\
\hline
\end{tabular}

The error values in the table show that the drift-flux model and homogenous model and Awad \& Muzychka, (2008) model are the most accurate models for pressure prediction as the values of AAPE, APE, average negative error and average positive error are the lowest compared to the other models. The Lockhart-Martinelli and Muller-Steinhagen \& Heck models can predict most of the experimental data within acceptable error and can be recommended as a guide for pressure drop prediction in multiphase flow systems. The Friedel model gives the highest percentage of errors and not recommendable for pressure drop prediction of multiphase flow in horizontal pipes.

Through analysis of Figures $6 a \& 6 b$, it can be observed that the assumption of multiphase flow as homogeneous flow is reasonable as the trend lines of experimental and predictions are very close. Ghajar (2005) considers that the homogenous model is more suitable for predicting pressure drop in bubbly flow patterns. The present results also confirm this behaviour once the homogenous model gives more accurate results for the bubbly flow cases of CWF and the low air 
flow rate $(5 \mathrm{l} / \mathrm{min})$ for CTF. The error increases for the cases of CTF with high volumetric quality when wavy stratified flow is observed. The discrepancy can be related to the original assumption, which is made in the equation of the homogeneous model, that the flow is homogenous and the velocities of the gas and liquid are the same.

By analysis of Fig. 7, it can be verified that the Lockhart-Martinelli' model is suitable for CWF cases as the error is lower compared to CTF. The higher error for CTF may be attributed to the change in the flow pattern to wavy stratified flow similar to homogenous model. Spedding et al. (2006) found that the Lockhart-Martinelli over/under predicts the data within $\pm 40 \%$ error especially in higher mass velocity values which are much higher than present study. Awad and Muzychka (2014a) and Quiben (2005), recommended that Lockhart-Martinelli as one of the best methods that can be used for predicting pressure drop in two-phase flow as it can be used for any flow pattern. The results in Fig. 7 demonstrate that at higher mass flux (Reynolds number) of the mixture, this method under predicts the data. This may be attributed to the assumptions considered in the development of the model such as: i) interaction between the two-phases is ignored, ii) the accelerations and static heads for the phases are neglected, therefore the pressure drop in gas and liquid phases is assumed to be the same.

From Fig. 8, it can be seen that the Friedel model gives a high discrepancy compared to the other correlations which is reflected in average error of $56 \%$ as given in table 3 . As it can be verified from the comparison, this model over predicts the experimental data. The present finding is supported by even higher error of $66 \%$ given by Xu et al (2013) and 83\% by Awad \& Muzychka (2014b). In contrast, some authors (Quiben (2005) and Ghajar (2005)) recommended the Friedel correlation is capable of providing the most accurate results for pressure drop analysis in two phase flows. The high discrepancy may be attributed to the difference in test operating condition, pipe diameter and using fluids of different densities. Friedel (2005) used R134a, R22 and R410A as test fluids in his study.

From Fig. 9 and Table 3, the MSH model under predicts the experimental data with a deviation of around $-12 \%$ which is almost similar to Lockhart-Martinelli' model. Awad and Muzychka (2014b) found that MSH method predicted their data within $36 \%$ error 
in $0.054 \mathrm{~m}$ ID pipe for water-gas two-phase flow which is even higher than present work. The increase of discrepancy at higher Reynolds number in this work was also reported Ould Didi, et al. (2002).

\section{Conclusion}

The effect of the volumetric quality and mixture velocity on pressure drop of air-water flow in horizontal pipes with different ID are investigated both experimentally and numerically, through various empirical correlations and by using of the drift-flux model. The superficial water velocity in the range of $0.16-5.263 \mathrm{~m} / \mathrm{s}$ and superficial air velocity in the range of $0.16-3.289 \mathrm{~m} / \mathrm{s}$ were used to give the different values of volumetric qualities. The pressure drop measurements were performed under constant water flow rate (CWF) and constant total flow rate (CTF). Through comparison between the pressure drop obtained by the models against the experimental acquisitions, the main findings can be summarised as follows:

- Single phase flow tests were performed and the results confirmed the accuracy of the instrumentation and the suitability of the test facility which can be used for two-phase flow investigation.

- The friction pressure drop enhanced with the increasing of gas flow rate for CWF. On the other hand, it decreased with the increasing of gas flow rate for CTF. This behaviour is attributed to the flow patterns transition in pipes.

- Drift-flux model predicts the experimental data with good accuracy. The average error is of around $0.8 \%$ which is the lowest compared to other models.

- The prediction from Homogenous and Awad \& Muzychka, (2008) models is concluded as the most accurate one compared to other empirical models in the literature to measure the friction pressure drop with an average percentage error less than $3 \%$.

The Lockhart-Martinelli and Muller-Steinhagen and Heck model are considered as the second best empirical models from the literature to predict the experimental data with satisfactory average percentage is less than $-12 \%$. 
- The Friedel model can be used as a guide to predict the pressure drop but it is not quantitatively reliable as the average percentage error is around $56 \%$.

\section{References}

Awad, M. M., Muzychka, Y. S., 2008, "Effective Property Models for Homogeneous Two-Phase Flows", Experimental Thermal and Fluid Science, Volume 33, No. 1, pp. 106-113.

Awad, M. M., 2012, Two-Phase Flow, An Overview of Heat Transfer Phenomena, Dr M. Salim Newaz Kazi (Ed.), InTech, DOI: 10.5772/54291. Available from: http://www.intechopen.com/books/an-overview-of-heat-transfer-phenomena/twophase-flow.

Awad, M.M., 20814, A Note on the Mixture Viscosity Using the Shannak Definition, Annals of Nuclear Energy, Volume 65, pp. 239-240.

Awad, M.M., Muzychka, Y.S., 2014a Modeling of Interfacial Component for TwoPhase Frictional Pressure Gradient at Microscales. Advances in Mechanical Engineering, 27 February, 6 (492435), 2-16.

Awad, M.M., Muzychka, Y.S., 2014b. A Robust Asymptotically Based Modeling Approach for Two-Phase Flows. Advances in Mechanical Engineering, 6 (327653), 1-10.

Awad, M.M., 2015, A Note on the Mixture Density Using the Shannak Definition, ASME Journal of Nuclear Engineering and Radiation Science, Volume 1, Issue 1, Article No. (014501), doi:10.1115/1.4026388.

Beattie, D.R.H., Whalley, P.B., 1982, A simple two-phase frictional pressure drop calculation method. International Journal of Multiphase Flow, 8, pp. 83-87.

Bhagwat, S. M., Ghajar, A. J., 2014, A flow pattern independent drift flux model based void fraction correlation for a wide range of gas-liquid two phase flow. International Journal of Multiphase Flow, 59, 186-205.

Bhagwat, S.M., Mollamahmutoglu, M., Ghajar, A.J., Experimental investigation and performance evaluation of isothermal frictional two phase pressure drop correlations in vertical downward gas-liquid two phase flow, Proceedings of the ASME 2012 Summer Heat Transfer Conference, July 8-12, 2012, Rio Grande, Puerto Rico, HT2012-58049.

Chen, I.Y., Yang, K.S., Chang, Y.J., Wang, C.C., 2001. Two-phase pressure drop of air-water and R-410a in small horizontal tubes. Int. J. Multiphase Flow, 27, 12931299. 
Choi, J.; Pereyra, E., Sarica, C., Park, C., Kang, J.M., 2012, An efficient drift flux closure relationship to estimate liquid holdups of gas-liquid two phase flow in pipes. Energies, 5, 5294-5306.

Chisholm, D., 1983. Two-phase flow in pipelines and heat exchangers. New York: Longman Inc.

Crowe, C.T., 2006, Handbook of multiphase flow, Washington State University.

Cui, X., Chen, J. J. J., 2010. A re-examination of the data of Lockhart-Martinelli. International Journal of Multiphase Flow, October , 36(10), 836-846.

Friedel, L., 1979. Improved friction pressure drop correlation for horizontal and vertical two-phase pipe flow. In: European Two-Phase Flow Group Meeting, Ispra, pp. 485-492.

Ghajar, A.J., 2005. Non-boiling heat transfer in gas-liquid flow in pipes - a tutorial. Journal of the Brazilian Society of Mechanical Sciences and Engineering, Vol. 27, pp. 46-55.

Hamad, F.A.; Ganesan, P., 2015, Effect of Drops on Turbulence of Kerosene-Water Two-Phase Flow in Vertical Pipe, International Journal of Heat and Fluid Flow 56, 152-159.

Hamayun, M., Palm, B. \& Rashid, A., 2010. Experimental investigation of two-phase pressure drop in a vertical mini-channel at three saturation pressures. Stockholm,, Applied Thermodynamics and Refrigeration, Royal Institute of Technology.

Holland, F. \& Bragg, R., 1995. Fluid Flow for Chemical Engineers. 2nd ed. Oxford: A division of reed educational and proffesional publishing Ltd .

Holland, F. A. \& Bragg, R., 1999. Two-phase multiplier. Oxford: ButterworthHeinemann.

Ivor, R.E., Geir, S.L.P., Mack, E.S., 2004. The Modelling of Multiphase System under Steady-State and Transient Conditions. PSIG Annual Meeting, 20-22 October, Palm Springs, California.

Kaji, M., Azzopardi, B.J., 2010. The effect of pipe diameter on the structure of gasliquid flow in vertical pipes. Int. J. Multiph. Flow, 36(4), 303-313.

Leveque, R.J., 2002. Finite volume methods for hyperbolic problems. Cambridge University Press.

Lockhart, R.W.; Martinelli, R.C., 1949. Proposed correlation of data for isothermal two-phase component flow in pipes. Chem. Eng. Prog., 45, 39-45.

Michaelides, E.E., Particles, Bubbles and Drops - Their Motion, Heat and Mass Transfer, World Scientific Publishers, New Jersey, 2006.

Mishima, K., Hibiki, T., 1996. Some characteristics of air-water two-phase flow in small diameter vertical tubes. Int. J. Multiphase Flow, 22, 703-712. 
Muller-Steinhagen, H., Heck, K., 1986, A simple friction pressure drop for two-phase flow in pipes. Chemical Engineering and Processing: Process Intensification, 20(6), 297-308.

Poesio, P., Strazza, D., Giorgio, S., 2009. Very-viscous-oil/water/airflow through horizontal pipes: Pressure drop measurement and prediction. Chemical Engineering Science, 64(11), 1136-1142.

Quiben, J., 2005. Experimenta and analytical styudy of two-phase pressure drops during evaporation in horizontal tubes , Lausanne: EPFL.

Risso, F., Roig, V., Amoura, Z., Riboux, G., Billet A.M., 2008. Wake attenuation in large Reynolds number dispersed two-phase flows. Phil. Trans. R. Soc. A, 366, 2177-2190.

Rodrigo Barraza, Gregory Nellis, Sanford Klein, Douglas Reindl, Measured and predicted frictional pressure drop for boiling zeotropic mixed refrigerants in horizontal tubes, International Journal of Heat and Mass Transfer, Volume 98, July 2016, Pages 285-298.

Santim, C.G.S. Rosa, E.S., 2016. Roe-type Riemann solver for gas-liquid flows using drift-flux model with an approximate form of the Jacobian matrix. International Journal for Numerical Methods in Fluids , 80(9), 536-568.

Serizawa, A., Kataoka, I., 1990, Turbulence Suppression in Bubbly Two-Phase Flow, Nuclear Engineering and Design, 122, 1-16.

Shannak, B.A., 2008, Frictional pressure drop of gas liquid two-phase flow in pipes. Nucl. Eng. 238 (12), 3277-3284.

Shen, X., J.P. Schlegel, S.W. Chen, S. Rassame, M.J. Griffiths, T. Hibiki and M. Ishii. 2014. Prediction of Void Fraction in Large Diameter Pipes Using Drift-Flux Models. Springer Briefs on Frontiers and Progress in Multiphase Flow I, Chapter 2. Springer, New York. DOI: 10.1007/978-3-319-04358-6_2

Spedding, P., Benard, E. \& Donnelly, G., 2006. Prediction of pressure drop in multiphase horizontal pipe flow. International Communications in Heat and Mass Transfer, 33(1), 1053-1062

Suwankamnerd, P. \& Wongwises, S., 2014. An experimental study of two-phase airwater flow and heat transfer characteristics of segmented flow in amicrochannel. Experimental Thermal and Fluid Science, 21 November , I(62), 29-39.

Thome, J., 1990. Enhanced Boiling Heat Transfer. Washington: Taylor \& Francis Inc. Xu, Y., Fang, X. Su, X., Zhou, Z. Chen, W., 2012. Evaluation of frictional pressure drop correlations for two-phase flow in pipes. Nuclear Engineering and Design, 253 , 86-97. 
Zuber, N. Findlay, J.A., 1965, Average volumetric concentration in two-phase flow systems. Journal of Heat Transfer-Transactions of the ASME 87, 453-468. 